\title{
Biochemical and biological characterization of exosomes containing prominin-1/CD133
}

\author{
Germana Rappa', Javier Mercapide, Fabio Anzanello', Robert M Pope ${ }^{2}$ and Aurelio Lorico ${ }^{1 *}$
}

\begin{abstract}
Exosomes can be viewed as complex "messages" packaged to survive trips to other cells in the local microenvironment and, through body fluids, to distant sites. A large body of evidence indicates a pro-metastatic role for certain types of cancer exosomes. We previously reported that prominin-1 had a pro-metastatic role in melanoma cells and that microvesicles released from metastatic melanoma cells expressed high levels of prominin-1. With the goal to explore the mechanisms that govern proteo-lipidic-microRNA sorting in cancer exosomes and their potential contribution(s) to the metastatic phenotype, we here employed prominin-1-based immunomagnetic separation in combination with filtration and ultracentrifugation to purify prominin-1-expressing exosomes (prom1-exo) from melanoma and colon carcinoma cells. Prom1-exo contained 154 proteins, including all of the 14 proteins most frequently expressed in exosomes, and multiple pro-metastatic proteins, including CD44, MAPK4K, GTP-binding proteins, ADAM10 and Annexin A2. Their lipid composition resembled that of raft microdomains, with a great enrichment in lyso-phosphatidylcholine, lyso-phosphatidyl-ethanolamine and sphingomyelin. The abundance of tetraspanins and of tetraspanin-associated proteins, together with the high levels of sphingomyelin, suggests that proteolipidic assemblies, probably tetraspanin webs, might be the essential structural determinant in the release process of prominin-1 of stem and cancer stem cells. Micro-RNA profiling revealed 49 species of micro-RNA present at higher concentrations in prom1-exo than in parental cells, including 20 with cancer-related function. Extensive accumulation of prom1-exo was observed $3 \mathrm{~h}$ after their addition to cultures of melanoma and bone marrow-derived stromal cells (MSC). Short-term co-culture of melanoma cells and MSC resulted in heterologous prominin-1 transfer. Exposure of MSC to prom1-exo increased their invasiveness. Our study supports the concept that specific populations of cancer exosomes contain multiple determinants of the metastatic potential of the cells from which they are derived.
\end{abstract}

Keywords: Exosomes, Melanoma, Prominin-1, Proteomics, Lipidomics, micro-RNA

\section{Introduction}

Development of effective anti-cancer strategies based on prevention and targeting of metastatic disease is of high priority, particularly for melanoma, a disease for which the development of metastasis is by far the major cause of patients' death [1]. Tumor-derived exosomes, small extracellular vesicles that perform diverse cellular functions including intercellular communication, antigen presentation, and transfer of proteins, RNA and lipids, have been recently implicated in the metastatic process. Exosomes originate by a sequential process of inward

\footnotetext{
* Correspondence: alorico@roseman.edu

${ }^{1}$ Cancer Research Center, Roseman University of Health Sciences, Las Vegas, NV 89135, USA

Full list of author information is available at the end of the article
}

budding of late endosomes, producing multivesicular bodies (MVBs), followed by release of internal microvesicles into the microenvironment by fusion of the MVBs with the plasma membrane [2]. Cancer exosomes may have a role in the cross-talk between primary tumors and bone marrow-derived stromal cells (MSC), reprogramming MSC and other non-tumor cells to support local cancer growth as well as to prime pre-metastatic niche(s) [3-7]. However, difficulties in obtaining homogeneous exosomal preparations result in incomplete understanding of exosome formation, composition and functions [8]. We recently reported a novel identification of the extracellular release of prominin-1-containing membrane microvesicles from human FEMX-I metastatic melanoma cells, and suggested that prominin-1 
microvesicles influence the metastatic capacity of FEMX-I cells [9]. Our laboratory had previously shown that prominin-1 knock-down resulted in decreased metastatic potential of FEMX-I cells in immune-deficient mice [10]. Prominin-1, a pentaspanning transmembrane protein originally identified as a surface marker of both neural [11] and hematopoietic [12] stem and progenitor cells, is expressed in both established melanoma cell lines and clinical specimens derived from melanoma patients [13-16].

Here, we have employed immune-selection forprominin-1 to isolate and characterize a homogenous preparation of exosomes, presumably engineered from FEMX-I melanoma cells to perform unique and prometastatic tasks in the local microenvironment.

\section{Experimental procedures \\ Cell Culture}

The human FEMX-I cell line was originally derived from a lymph node metastasis of a patient with malignant melanoma [17]. Cells were routinely cultured in RPMI (Mediatech Inc., Manassas, VA, http://www.cellgro.com) supplemented with $10 \%$ fetal bovine serum (FBS) (Atlanta Biologicals, Lawrenceville, GA, http://www.atlantabio. com) at $37^{\circ} \mathrm{C}$ in a $5 \% \mathrm{CO}_{2}$ humidified incubator and used between passages 3 and 15. Human MSC were obtained from Dr. Prockop, Texas A \& M. They were isolated from 1 to $4-\mathrm{ml}$ bone marrow aspirates taken from the iliac crest of normal adult donors after informed consent and under a protocol approved by the Texas A \& M Institutional Review Board, prepared as described by Larson et al. [18], and frozen at passage 1 . For expansion, MSC were plated in a $75-\mathrm{cm}^{2}$ culture dish, and incubated for 1 day, to recover viable adherent cells. Cultures contained approximately $50 \%$ of rapidly self-renewing cells (RS) and 50\% of larger, more slowly dividing and more mature cells (MS). MSC were then replated at 50 cells per $\mathrm{cm}^{2}$ and incubated for 10 days before lentiviral transduction. With time in culture, the percentage of RS cells decreased progressively to less of $10 \%$ of the total cells. All cell lines were stored in aliquots in liquid nitrogen and kept in culture for less than 3 months. Complete culture medium for MSC consisted of $\alpha$-minimal essential medium (Gibco, Grand Island, $\mathrm{NY}$ ), 17\% fetal bovine serum (lot selected for rapid growth of MSC) (Atlanta Biologicals), 100 units $/ \mathrm{ml}$ penicillin, 100 $\mu \mathrm{g} / \mathrm{ml}$ streptomycin, and $2 \mathrm{mM}$ L-glutamine. Cells were routinely tested for mycoplasma contamination by the Venor GeM mycoplasma detection kit (Sigma-Aldrich, St. Louis, MO) and by DAPI staining and authenticated by morphology check every two weeks.

\section{Preparation of microvesicles and exosomes}

For preparation of FEMX-I microvesicles ("classical" preparation) and exosomes (prom1-exo), cells were enzymatically detached and cultured for six days as spheroids in serum-free medium, consisting of Dulbecco's modified Eagle's medium in the presence of B27 supplement (both from Gibco) in tissue culture plates, as previously described [9]. At time of harvest, the $\mathrm{pH}$ of the medium was 6.7. "Classical" microvesicle preparations were performed by differential centrifugation at $4^{\circ} \mathrm{C}$ at $300 \times \mathrm{g}$ for $5 \mathrm{~min}$, then at $500 \times \mathrm{g}$ for $5 \mathrm{~min}$., at $1,200 \times \mathrm{g}$ for $20 \mathrm{~min}$. and at $10,000 \times \mathrm{g}$ for $30 \mathrm{~min}$, followed by centrifugation at $200,000 \times \mathrm{g}$ for $60 \mathrm{~min}$ at $4^{\circ} \mathrm{C}$. Because these preparations are likely to contain a mixture of both exosomes and other microvesicles, we have used the generic term microvesicles in this study to include the exosome pool. Prom1-exo were prepared by differential centrifugation at $4^{\circ} \mathrm{C}$ at $300 \times \mathrm{g}$ for $5 \mathrm{~min}$, then at $500 \times \mathrm{g}$ for $5 \mathrm{~min}$., at $1,200 \times \mathrm{g}$ for $20 \mathrm{~min}$. and at $10,000 \times \mathrm{g}$ for $30 \mathrm{~min}$, followed by filtration with a $0.22 \mu \mathrm{m}$ low-protein binding Millex-GV filters (Millipore); the $10,000 \times \mathrm{g}$ supernatant was then concentrated by Amicon Ultracel-100K (Millipore) tubes according to the manufacturer's instructions. The concentrate was diluted 1:1 (v/v) with PBS; incubated with antiIgG microbeads (Miltenyi Biotec, Auburn, CA) for $90 \mathrm{~min}$ at $4^{\circ} \mathrm{C}$, and passed through LS-columns according to the manufacturer's instructions. The flow-through was collected, incubated with anti-human-prominin-1 beads (Miltenyi) for $1 \mathrm{~h}$, and passed through LS-columns. After washings, the column was removed from the magnet and prom1-exo were flushed down with $10 \mathrm{ml}$ of cold PBS. Prom1-exo were then centrifuged at 200,000 g for $60 \mathrm{~min}$ at $4^{\circ} \mathrm{C}$ and resuspended in PBS. Each exosomal preparation was checked by nanoparticle tracking analysis for size distribution and microparticle concentration and by Western blotting for expression of prominin-1. Exosomes and microvesicles were stained with PKH67 (Sigma-Aldrich, St. Louis, MO), according to the manufacturer's protocol.

\section{Nanoparticle tracking analysis (NTA)}

We used the light-scattering characteristics of $488 \mathrm{~nm}$ laser light on microvesicle preparations undergoing Brownian motion injected by continuous flow into the sample chamber of an LM10 unit (Nanosight, Amesbury, UK). Three videos of 60-90 seconds were recorded of each sample. Data analysis was performed with NTA 2.3 software (Nanosight). The diffusion coefficient and hydrodynamic radius were determined using the Stokes-Einstein equation, and results were displayed as a particle size distribution. Data are presented as the average and standard deviation of the three video recordings. Since NTA is most accurate between particle concentrations in the range of $2 \times 10^{8}$ to $2 \times 10^{9} / \mathrm{ml}$, when samples contained higher numbers of particles, they were diluted before analysis and the relative concentration calculated according to the dilution factor. Control 100 and $200 \mathrm{~nm}$ beads were supplied by Nanosight. NTA of a small sample of any given 
preparation revealed that they were essentially monodisperse, excluding the problem of aggregation, which may significantly impact on a biological system.

\section{Prominin-1-EGFP fusion plasmid and transfection}

We employed the eukaryotic expression plasmid enhanced GFP (pEGFP)-N1-prominin-1, containing the entire coding sequence of human prominin-1 fused in-frame to the N-terminus of GFP [19], to transfect FEMX-I cells, as previously described [9].

\section{Protein processing and LC-MS/MS}

\section{Electrophoresis}

Three independent preparations of prom1-exo were analyzed by LC-MS/MS. Samples, $5 \mu \mathrm{g}$ each according to results of Bradford assays, were individually mixed with $20 \mu \mathrm{l}$ LDS buffer, divided into four fractions and loaded on NuPage 4-12\% Bis-Tris precast gels (Invitrogen, Carlsbad, CA). Two exterior lanes were loaded with Sharp pre-stained protein ladder standards (Invitrogen) and the gel was electrophoresed according the manufacturer's recommendations. Two lanes, one containing Sharp prestained standards and one containing one fourth of the total sample, were visualized using a silver nitrate protocol (QuickSilver, Pierce, Madison, WI), then realigned with the unstained gel section to create a template for excision. The three remaining, unstained lanes were segmented into 14 equal sections and subjected to in-gel tryptic digestion following the procedure of Shevchenko et al. [20]. Briefly, the protocol calls for reduction with $10 \mathrm{mM}$ DTT and alkylation with $55 \mathrm{mM}$ iodoacetamide (SIGMA-Aldrich, St. Louis, Mo). Each segment was prepared with successive wash and dehydration steps using $50 \mathrm{mM}$ ammonium bicarbonate (AmBic) or $50 \%$ acetonitrile containing $50 \mathrm{mM} \mathrm{AmBic}$, respectively. Finally, the shrunken gel segments were rehydrated with ice cold AmBic containing $12 \mathrm{ng} / \mathrm{ml}$ sequencing grade trypsin (Promega, Madison, WI), and allowed to swell on ice for three hours. Digestions were then carried out for $16 \mathrm{~h}$ at $57^{\circ} \mathrm{C}$. The quality of the digested supernatant was determined prior to lyophilization by spotting $1 \mu \mathrm{l}$ aliquots mixed 1:1 with a saturated solution of alpha-cyano-4-hydroxycinnamic acid (CHCA) acid in $0.1 \%$ trifluroacetic acid (Pierce) and $50 \%$ acetonitrile onto a stainless steel target plate with subsequent MALDI/TOF analysis on a Autoflex III TOF/TOF (Bruker, Billerica, MA). The remainder of the gel extract was diluted prior to loading on home-brew StageTips desalting microtip using as previously described[21]. Material eluted below 50\% acetonitrile was lyophilized and the concentrated peptides were rehydrated in $15 \mu \mathrm{L}$ of $0.1 \%$ formic acid with $5 \% \mathrm{LC} /$
MS-grade acetonitrile and $4 \mathrm{uL}$ was used for each $\mathrm{LC}$ injection.

\section{LC-MS/MS analysis}

Using a Dionex 3000 nanoRSLC series HPLC system (Thermo-Electron, Waltham, MA) recovered peptides were loaded at $2 \mu \mathrm{l} / \mathrm{min}$ onto a $200 \mu \mathrm{m}$ id by $2.5 \mathrm{~cm}$ precolumn (New Objective, Woburn, MA) packed with $5 \mu \mathrm{m}$ YMC ODS-C18 beads (Waters, Milford, MA). Following an on-line desalting step, trap flow was rerouted through a self-packed $75 \mathrm{um}$ id $\times 9 \mathrm{~cm}$ analytical column containing $3 \mu \mathrm{m}$ Halo solid-core C-18 particles with 300 Angstrom pore size. A distal spray opening 8 to 10 microns in diameter restricted the hand-packed column. A linear gradient from $95 \%$ buffer A [0.1\% formic acid, 5\% acetonitrile and 94.9\% LCMS grade water] to $55 \%$ buffer $\mathrm{B}$ [ $90 \% \mathrm{ACN}, 9.9 \%$ water and $0.1 \% \mathrm{FA}$ ] was delivered at $200 \mu \mathrm{l} / \mathrm{min}$ over $70 \mathrm{~min}$ using a second nano-capacity pump. Following this, the composition of buffer B was ramped to $80 \%$ over $5 \mathrm{~min}$, maintained for $5 \mathrm{~min}$ and finally decreased to $5 \%$ over the final $10 \mathrm{~min}$.

LC effluent was directed to the electrospray source of a linear ion-trap mass spectrometer (LTQ/XL, ThermoElectron, USA). MS/MS spectra were acquired in a datadependent acquisition mode that automatically selected and fragmented the five most abundant peaks from each MS spectrum. MS.MS scans were recorded in centroid mode targeting 8000 counts. The trap was filled for a maximum of $10 \mathrm{~ms}$ prior to isolation of the target peptide at an average value 1E04.

\section{Database searching}

Tandem mass spectra were processed and charge states ascertained without deisotoping by Mascot Distiller version 2.4. All MS/MS samples were analyzed using batch processing with the Mascot Daemon interface (version 2.4, Matrix Science) and MASCOT search engine (version 2.4 Matrix Science) [21]. All spectral files were also searched using Spectrum Mill Proteomics Workbench (Rev.Rev A.03.02.060, Agilent Technologies, Santa Clara, CA) and X! Tandem (The GPM, thegpm.org; version CYCLONE (2010.12.01.1)). All three engines were set up to search SwissProt_2012_09.fasta (selected for Homo sapiens, Nov. 24 2012, 20,235 entries) assuming the digestion enzyme trypsin and considering up to two missed cleavages. X! Tandem searches were restricted to the subset of proteins assigned with either Mascot or Spectrum Mill.

Mascot, Spectrum Mill and X! Tandem were searched with a fragment ion mass tolerance of $0.40 \mathrm{Da}$ and a parent ion tolerance of 1.8 Da. Mascot's Carbamidomethylation of cysteine was specified in Mascot and X! Tandem as a fixed modification. Oxidation of methionine, carbamidomethylation of lysine were specified in 
X!Tandem and Mascot as variable modifications. Oxidation of methionine was the only variable modification specified in SpectrumMill.

\section{Criteria for protein identification}

Scaffold (version Scaffold_4.0.0, Proteome Software Inc., Portland, OR) was used to validate MS/MS based peptide and protein identifications. Peptide identifications were accepted if they could be established at greater than $90.0 \%$ probability by the Peptide Prophet algorithm [22]. Protein identifications were accepted if they could be established at greater than $99.0 \%$ probability and contained at least 4 identified peptides. The Protein Prophet algorithm as implemented in Scaffold_4.0.0, assigned protein probabilities [23]. Proteins that contained similar peptides and could not be differentiated based on MS/MS analysis alone were grouped to satisfy the principles of parsimony. Specifically the fragmentation patterns of distinct peptides from families of homologous proteins were inspected manually using the protocol described by Tabb et al. [24]. Hence, validating at least four unique peptides for each protein listed individually minimized protein ambiguity. Peptide False Discovery Rates (FDR) were also estimated using Target: Decoy search as described by Elias and Gygi $[25,26]$, with $\mathrm{FDR}=2 \times$ (no. of PSM in the decoy) $/$ (No. of all PSM), where PSM are the peptide spectral matches with better than $90 \%$ probability as described above. The FDR calculated by this approach, $0.1 \%$, likely benefits from probabilistically merging multiple search algorithms [23].

\section{Immunoblotting}

For immunoblotting, microvesicles and prom1-exo resuspended in PBS were checked for consistency by NTA. Aliquots of microvesicles, exosomes and FEMX-I total cell lysates containing $1-10 \mu \mathrm{g}$ of protein were mixed 1:1 with SDS sample buffer (NuSep, Bogart, GA) containing 2\% 2-mercaptoethanol, boiled for $5 \mathrm{~min}$, and loaded onto a $8 \%$ Tris/Glycine/SDS gel. Electrophoretic separation of proteins was performed at a constant voltage of $120 \mathrm{~V}$ for $2 \mathrm{~h}$, and electrophoretic transfer of the proteins into Hybond ECL membrane (GE Healthcare, Waukesha, WI) was carried out at constant amperage (30 mA) for $15 \mathrm{~h}$. The blots were blocked with 5\% dry milk in Tris-buffered saline containing $0.05 \%$ Tween 20 (pH 7.5), antibody, and incubated with W6B3C1 antiprominin-1 (Miltenyi Biotec, Auburn, CA), or alix 3A9 clone (Cell Signaling Technology, Danvers, MA) at 1:1000 dilution in TBS-T for $5 \mathrm{~h}$ at room temperature. After washing with TBS-T, blots were incubated with IRDye $800 \mathrm{CW}$ secondary antibody (Li-Cor Biosciences, Lincoln, NE) in TBS-T $(1: 20,000)$ for $45 \mathrm{~min}$ at room temperature. Finally, blots were washed with TBS-T, scanned by Odyssey infrared imaging system and analyzed by Odyssey 2.1 application software (Li-Cor Biosciences). Gel band densitometric quantification was performed employing the ImageJ64 software (rsbweb.nih. gov/ij).

\section{ESI-MS/MS lipid profiling}

An automated electrospray ionization (ESI)-tandem mass spectrometry approach was used, and data acquisition and analysis were carried out as described previously $[27,28]$ with modifications. The lipid extracts from the FEMX-I cell pellets were dissolved in $1 \mathrm{ml}$ chloroform. An aliquot of $50 \mu \mathrm{l}$ of each extract in chloroform was used for analysis. Precise amounts of internal standards, obtained and quantified as previously described [29], were added in the following quantities (with some small variation in amounts in different batches of internal standards): $0.6 \mathrm{nmol}$ di12:0-PC, $0.6 \mathrm{nmol}$ di24:1PC, $0.6 \mathrm{nmol}$ 13:0-lysoPC, $0.6 \mathrm{nmol}$ 19:0-lysoPC, $0.3 \mathrm{nmol}$ di12:0-PE, 0.3 nmol di23:0-PE, 0.3 nmol 14:0-lysoPE, $0.3 \mathrm{nmol}$ 18:0-lysoPE, $0.3 \mathrm{nmol}$ di14:0-PG, $0.3 \mathrm{nmol}$ di20:0(phytanoyl)-PG, $0.3 \mathrm{nmol}$ di14:0-PA, $0.3 \mathrm{nmol}$ di20:0(phytanoyl)-PA, $0.2 \mathrm{nmol}$ di14:0-PS, $0.2 \mathrm{nmol}$ di20:0 (phytanoyl)-PS, and $0.23 \mathrm{nmol}$ 16:0-18:0-PI. The sample and internal standard mixture was combined with solvents, such that the ratio of chloroform $/$ methanol $/ 300$ $\mathrm{mM}$ ammonium acetate in water was $300 / 665 / 35$, and the final volume was $1.4 \mathrm{ml}$. The microvesicle samples were prepared similarly, except that the entire sample was analyzed, $1 / 3$ of the above standard amounts were added, and the final volume was $0.75 \mathrm{ml}$. The unfractionated lipid samples with internal standards were introduced by continuous infusion into the ESI source on a triple quadrupole MS/MS (API 4000, Applied Biosystems, Foster City, CA). Samples were introduced using an autosampler (LC Mini PAL, CTC Analytics AG, Zwingen, Switzerland) fitted with the required injection loop for the acquisition time and presented to the ESI needle at $30 \mu \mathrm{l} / \mathrm{min}$. Sequential precursor and neutral loss scans of the extracts produce a series of spectra with each spectrum revealing a set of lipid species containing a common head group fragment. Lipid species were detected with the following scans: PC and lysoPC, $[\mathrm{M}+\mathrm{H}]^{+}$ions in positive ion mode with Precursor of 184.1 (Pre 184.1); PE and lysoPE, [M + $\mathrm{H}]^{+}$ions in positive ion mode with Neutral Loss of 141.0 (NL 141.0); PG, $\left[\mathrm{M}+\mathrm{NH}_{4}\right]^{+}$in positive ion mode with $\mathrm{NL}$ 189.0 for PG; PI, $\left[\mathrm{M}+\mathrm{NH}_{4}\right]^{+}$in positive ion mode with $\mathrm{NL} 277.0$; PS, $[\mathrm{M}+\mathrm{H}]^{+}$in positive ion mode with $\mathrm{NL}$ 185.0; PA, $\left[\mathrm{M}+\mathrm{NH}_{4}\right]^{+}$in positive ion mode with $\mathrm{NL}$ 115.0. SM was determined from the same mass spectrum as PC (precursors of $\mathrm{m} / \mathrm{z} 184$ in positive mode) $[27,30]$ and by comparison with $\mathrm{PC}$ internal standards using a molar response factor for SM (in comparison with PC) determined experimentally to be 0.39 . The collision gas 
pressure was set at 2 (arbitrary units). The collision energies, with nitrogen in the collision cell, were $+28 \mathrm{~V}$ for PE, $+40 \mathrm{~V}$ for PC (and SM), $+25 \mathrm{~V}$ for PA, PI and PS, and +20 $\mathrm{V}$ for PG. Declustering potentials were $+100 \mathrm{~V}$ for all lipids. Entrance potentials were $+15 \mathrm{~V}$ for $\mathrm{PE}$ and $+14 \mathrm{~V}$ for PC (and SM), PA, PG, PI, and PS. Exit potentials were $+11 \mathrm{~V}$ for PE and $+14 \mathrm{~V}$ for PC (and SM), PA, PG, PI, PS. The scan speed was 50 or $100 \mathrm{u}$ per sec. The mass analyzers were adjusted to a resolution of $0.7 \mathrm{u}$ full width at half height. For each spectrum, 9 to 150 continuum scans were averaged in multiple channel analyzer (MCA) mode. The source temperature (heated nebulizer) was $100^{\circ} \mathrm{C}$, the interface heater was on, $+5.5 \mathrm{kV}$ or $-4.5 \mathrm{kV}$ were applied to the electrospray capillary, the curtain gas was set at 20 (arbitrary units), and the two ion source gases were set at 45 (arbitrary units). The background of each spectrum was subtracted, the data were smoothed, and peak areas integrated using a custom script and Applied Biosystems Analyst software, and the data were isotopically deconvoluted. The first and typically every $11^{\text {th }}$ set of mass spectra were acquired on the internal standard mixture only. Peaks corresponding to the target lipids in these spectra were identified and molar amounts calculated in comparison to the two internal standards on the same lipid class, except for PI, which was quantified in relation to a single internal standard. Ether-linked (alk(en)yl,acyl) lipids were quantified in comparison to the diacyl compounds with the same head groups without correction for response factors for these compounds as compared to their diacyl analogs. To correct for chemical or instrumental noise in the samples, the molar amount of each lipid metabolite detected in the "internal standards only" spectra was subtracted from the molar amount of each metabolite calculated in each set of sample spectra. The data from each "internal standards only" set of spectra was used to correct the data from the following 10 samples. Finally, the data were corrected for the fraction of the sample analyzed and normalized to the $\mathrm{mg}$ protein to produce data in the units $\mathrm{nmol} / \mathrm{mg}$.

\section{miRNA profiling}

The miRNA profiling array was carried out using Applied Biological Materials miRNA profiling service (ABM C201). Total RNA from FEMX-I cells and exosomes was prepared byQiazol extraction followed by poly-A tailing reactions and miRNA cDNA synthesis (ABM C204). 250 ng of cell's total RNA and exosomes' RNA were used in cDNA synthesis. Both cells' and exosomes' cDNA synthesis were carried out simultaneously and equal volume of cDNA synthesis reaction product was used in the subsequent profiling. The $\mathrm{Ct}$ values for each miRNA-specific cDNA were compared between FEMX-I cells and exosomes. Real-time qPCR reactions and instrumental analysis was performed using
Roche LightCycler480. Lists of miRNAs were generated by pair-wise comparison of our expression data sets (cells vs exosomes). Differentially expressed miRNAs were analyzed by the Ingenuity Pathway Analysis software (Ingenuity Systems, Redwood City, CA) to identify the biological functions that were most significant to the data sets.

\section{Immunofluorescence}

Cells were seeded on poly-L-lysine coated chamber slides and grown overnight. Following aspiration of media, cells were fixed in $4 \%$ paraformaldehyde (PFA), washed with PBS, permeabilized in $0.5 \%$ Tween 20 and blocked with goat serum. After washing with PBS, cells were incubated overnight at $4^{\circ} \mathrm{C}$ with primary antibodies in $1 \%$ BSA-PBS, followed by washes and a 45 -minutes incubation at room temperature with fluorochromelabeled secondary antibody in 1\% BSA in PBS. Fluorescent cells were analyzed by a CKX41 fluorescence inverted microscope (Olympus, Center Valley, PA).

\section{Invasion assay}

In vitro invasion assays were performed in BioCoat invasion chambers holding matrigel-coated- $8 \mu \mathrm{m}$-pore PET membrane cell culture inserts, using non-coated inserts as control (both from BD Biosciences, San Jose, CA), according to the manufacturer's directions. The matrigel layers of the invasion chambers were rehydrated with serum-free medium. The lower chambers were filled with medium containing $2 \% \mathrm{FBS}$, and equal aliquots of cells, pre-incubated for $3 \mathrm{~h}$ with or without prominin-1 -purified exosomes, were added in serum-free medium to the inserts. Following $24 \mathrm{~h}$ incubation at $37^{\circ} \mathrm{C}$, the cells on the upper side of the membrane were gently removed with wet sterilized cotton swabs. The cells on the lower surface of the membranes were fixed with $4 \%$ para-formaldehyde for $10 \mathrm{~min}$, and then stained with DAPI. The number of cells was counted in 8-12 randomly selected 10X-microscopic fields per insert using an Olympus CKX41 fluorescence microscope (Olympus America Corp., Center Valley, PA), and matrigel invasiveness expressed as the percentage of the number of matrigel-invading cells with respect to the control of chemotactic migration.

\section{Results}

\section{Exosomal preparation}

We previously reported that human FEMX-I metastatic melanoma cells released into the extracellular medium prominin-1-expressing microvesicles [9]. To investigate their nature, we cultured FEMX-I cells as spheroids under serum-free conditions for six days and compared a "classical" microvesicle preparation, based on differential centrifugation [9], with a prominin $-1^{+}$preparation, 
illustrated in Figure 1A, based on the combination of differential centrifugation, filtration and prominin-1based immuno-magnetic selection (prom1-exo). The final $\mathrm{pH}$ at time of harvest was 6.7, which resembled in vivo tumor growth conditions, where low $\mathrm{pH}$ condition is a hallmark of tumor malignancy, particularly for malignant melanoma cells, which, differently from normal cells, can survive in an acidic microenvironment [31]. Low $\mathrm{pH}$ conditions reportedly increase exosome release and uptake by cancer cells [32]. We used serumfree medium in the present study because serum supplements (such as fetal calf serum) often contain vesicles as well as aggregates of serum proteins, which may interfere with the isolation and characterization of FEMX-I exosomes. By NTA, we determined both size distribution and relative concentration of microvesicles and prom1exo in the supernatants of FEMX-I cells. As shown by NTA of PKH67-stained microvesicles, the "classical" microvesicle preparation showed several peaks, ranging from 70 to $550 \mathrm{~nm}$, while prom1-exo yielded a single peak of about $100 \mathrm{~nm}$ (Figure 1B); persistent binding of antiprominin-1 $50 \mathrm{~nm}$-immunomagnetic beads resulted in an apparent over-estimation of the exosomal size and broadening of the size distribution peak. The concentration of microvesicles and prom1-exo in FEMX-I supernatant were $3 \pm 0.4 \times 10^{9} / \mathrm{ml}$ and $0.35 \pm 0.2 \times 10^{9} / \mathrm{ml}$, respectively.
We then employed the same methodology (Figure 1A) to investigate whether it was possible to isolate prom1-exo from different prominin-1-expressing cancer cell lines. We found that prominin-1-immunomagnetic selection resulted in isolation of cancer exosomes also from human prominin-1-expressing Caco-2 colon carcinoma cells (Figure 1B). An approximately 10-fold difference in concentration of microvesicles and prom1-exo was found also in the cell supernatants of Caco- 2 cells $\left(1.5 \pm 0.35 \times 10^{9} / \mathrm{ml}\right.$ and $0.18 \pm 0.05 \times 10^{9} / \mathrm{ml}$, respectively). Similarly to what we observed in FEMX-I cells, Caco-2 cells microvesicles had a broad size range, while prom1-exo had a single 100 nm-peak.

\section{Proteome of prominin- $1^{+}$microvesicles}

Comparison of total cell lysates, microvesicles and prom1-exo from FEMX-I cells by Western blotting (Figure 2) revealed a great enrichment in prominin-1 and in the exosomal protein alix in prom1-exo vs. the FEMX-I cells themselves (53- and 184-fold for prominin-1 and alix, respectively) and vs. microvesicles (78- and 168-fold for prominin-1 and alix, respectively). To investigate whether they had the biochemical characteristics of bona fide exosomes, we analyzed the proteolipidic composition of prom1-exo from FEMX-I cells. Three independent preparations were used to

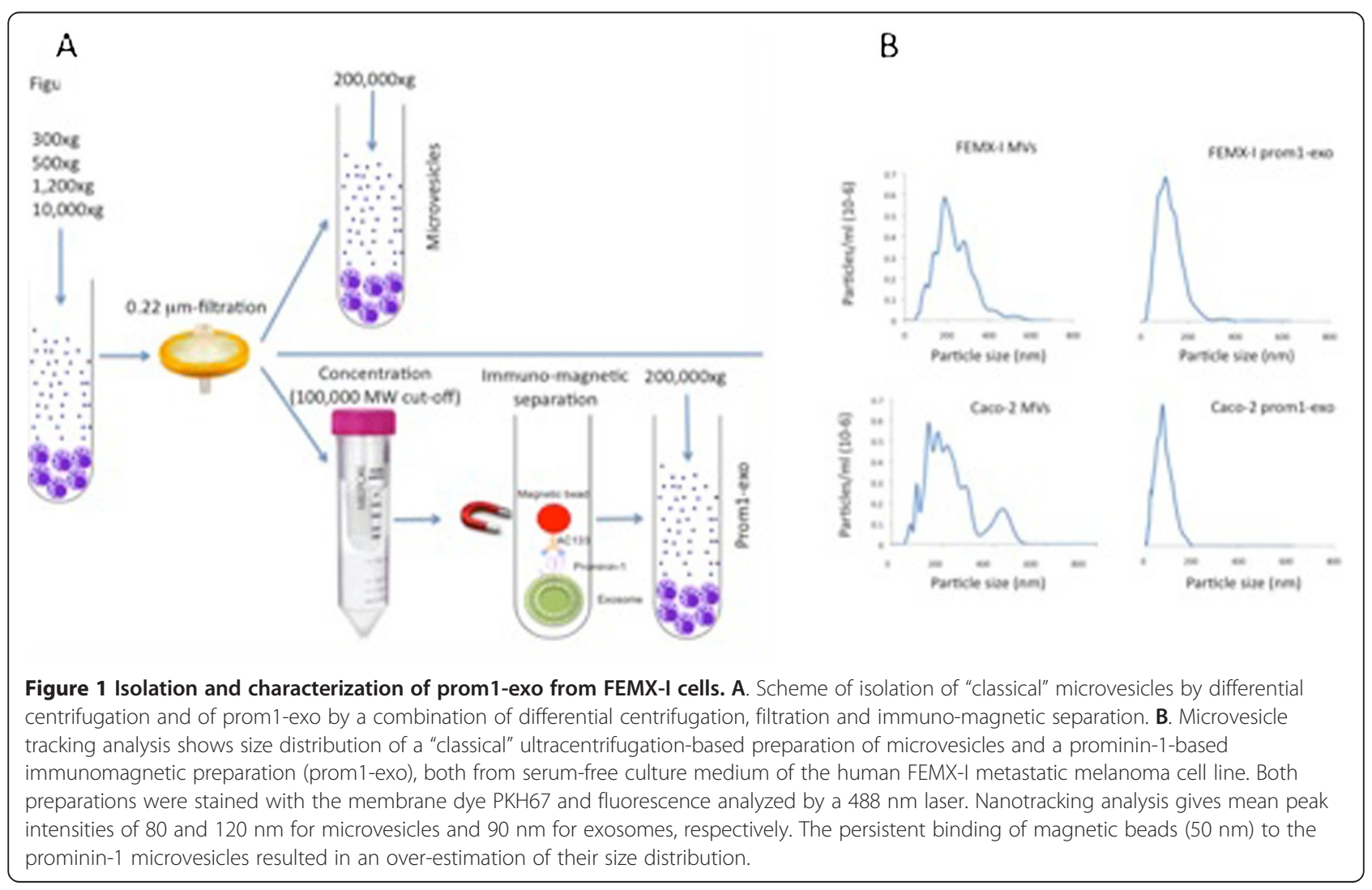




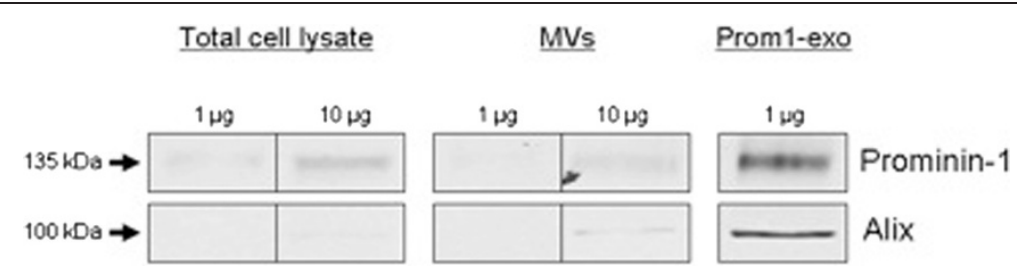

Figure 2 Enrichment of prominin-1 and alix in prom1-exo. Immunoblotting analysis of total cell lysates, microvesicles (MVs), and prom1-exo from FEMX-I cells. 1 and $10 \mu \mathrm{g}$ of total proteins were loaded per lane for total cell lysates and MVs and $1 \mu \mathrm{g}$ for prom1-exo, and analyzed as described under Experimental Procedures.

determine their protein composition via MS/MS mass spectrometry (see search methods in Additional file 1: Table S1). A total of 282 proteins were confidently assigned across all three samples (Additional file 2: Table S2 and Additional file 3: Table S3). We further highlighted an ensemble of proteins among which could be verified with two or more stringent peptide spectral matches (PSM) in all three replicates or those observed with three or more stringent PSM in any two replicates (Additional file 4: Table S4). This subset of 154 proteins is highly enriched for physiological processes (Additional file 5: Figure S1), involving membrane bound vesicles [count 40, p-value 6.4E-21] and endocytosis [count 20, p-value 7.3E-11] complexes, and including all of the 14 proteins most expressed in exosomes according to the compilation of peer-reviewed data hosted on the Exocarta site [33] (Table 1). Since the biogenesis of exosomes takes place in late endosomes to end up in multivesicular bodies (MVB), we first checked our list of proteins for those known to be involved with that particular compartment (Table 2). Reassuringly, we identified the bro1 domain-containing proteins alix and brox, known to function in association with the ESCRT (Endosomal Sorting Complex Required for Transport) pathway to help mediate intraluminal vesicle formation at multivesicular bodies and the abscission stage of cytokinesis. Various ESCRT components, central to MVB biogenesis, were identified in prom1-exo, including five ESCRT-I proteins [34], three ESCRT-III proteins and many other ESCRT-associated proteins (Table 2). Other proteins, related to their endosomal origin, were identified, including membrane transport and fusion proteins (GTPases, Annexin A2, A4, A5, A6 and A11); eight tetraspanins (TSPAN 4,6,9,14; CD63; CD81; CD82; CD9), and five Rab proteins (Additional file 4: Table S4). Interestingly, the immunosuppressive Immunoglobulin superfamily member 8 (IgSF8), also named CD81 partner 3, known to interact with CD81, CD9 and CD82 as well as with integrin alpha-3/beta-1 and integrin alpha-4/ beta-1, was highly expressed. The absence of endoplasmic reticulum proteins, such as calnexin and Grp78, and of Golgi proteins, such as GM130, indicated no contamination of vesicles of other compartments in prom1-exo preparations.

Table 1 Prom1-exo composition includes all the 14 most-expressed exosomal proteins (Exocarta)

\begin{tabular}{|c|c|c|c|c|}
\hline Protein name & Gene symbol & Accession number & Max N. of unique peptides & Max \% coverage \\
\hline Heat shock cognate $71 \mathrm{kDa}$ protein & HSPA8 & P11142 & 46 & 75 \\
\hline CD9 Antigen & CD9 & P21926 & 8 & 29 \\
\hline Glyceraldehyde-3-phosphate dehydrogenase & GAPDH & P04406 & 19 & 66 \\
\hline Actin, cytoplasmic 1 & ACTB & P60709 & 22 & 74 \\
\hline CD63 Antigen & CD63 & P08962 & 5 & 22 \\
\hline CD81 Antigen & CD81 & P60033 & 7 & 32 \\
\hline Annexin A2 & ANXA2 & P07355 & 17 & 52 \\
\hline Alpha-enolase & ENO1 & P06733 & 20 & 62 \\
\hline Heat shock protein HSP 90-alpha & HSP90AA1 & P07900 & 13 & 6 \\
\hline Elongation factor 1-alpha 1 & EEF1A1 & P68104 & 8 & 29 \\
\hline Pyruvate kinase isozymes M1/M2 & PKM & P14618 & 21 & 59 \\
\hline 14-3-3 protein epsilon & YWHAE & P62258 & 6 & 36 \\
\hline Syntenin-1 & SDCBP & 000560 & 20 & 86 \\
\hline Programmed cell death 6-interacting protein & PDCD6IP & Q8WUM4 & 63 & 75 \\
\hline
\end{tabular}


Table 2 Prom1-exo composition includes many ESCRT and ESCRT-associated proteins

\begin{tabular}{lcccc}
\hline $\begin{array}{l}\text { Protein } \\
\text { category }\end{array}$ & $\begin{array}{c}\text { Gene } \\
\text { name }\end{array}$ & $\begin{array}{c}\text { Accession } \\
\text { number }\end{array}$ & $\begin{array}{c}\text { Max N. of } \\
\text { unique } \\
\text { peptides }\end{array}$ & $\begin{array}{c}\text { Max \% } \\
\text { coverage }\end{array}$ \\
\hline ESCRT-I & VPS-28 & Q9UK41 & 9 & 57 \\
& VPS-37B & Q9H9H4 & 9 & 55 \\
& FAM125A & Q96EYS & 6 & 37 \\
& FAM125B & Q9H7P6 & 5 & 38 \\
ESCRT-III & TSG101 & Q99816 & 13 & 37 \\
& CHMP2A & O43633 & 3 & 16 \\
ESCRT-associated & CHMP4B & Q9H444 & 6 & 35 \\
proteins & CHMP5 & Q9NZZ3 & 4 & 31 \\
& PDCD6IP & Q5WW32 & 10 & 40 \\
& Q8WUM4 & 63 & 75 \\
& VPS-4A & Q9UN37 & 9 & 22 \\
& MITD1 & Q8WW92 & 6 & 36 \\
& IST1 & P53990 & 11 & 33 \\
& HSPA1A & P08107 & 17 & 46 \\
& HSPA8 & P11142 & 46 & 75 \\
\hline
\end{tabular}

Other cancer-related proteins and/or proteins implicated in cancer progression were identified, including CD44 [35], Hsp70 [36], annexin A2 [37-40], as well as components involved in Wnt (SFRP1 = secreted frizzledrelated protein 1) and Ras signaling, including the GTPbinding proteins Rap1b and Rap2b, reportedly involved in the activation of ERKs [41], the 14-3-3 protein, a family of exosomal proteins that have a matrix metalloproteinase-1 stimulating effect for dermal fibroblasts [42], and disintegrin and metalloproteinase domain-containing protein 10 (ADAM 10) (Additional file 4: Table S4). A perinuclear pool of prominin-1, associated with integrin-beta 1 (CD29), expressed in FEMX-I exosomes, was detected by fluorescence microscopy (Figure 3). Interestingly, a striking correspondence between prominin-1 and CD29 in FEMX-I cells was observed, suggesting their co-localization in endosomal compartments.

\section{Prom1-exo have a typical lipid raft composition}

A lipid composition analysis of prom1-exo and parental FEMX-I cells was performed through ESI MS/MS (Figures 4 and 5). A typical lipid raft composition of prom1-exo was observed, with $400 \%$ increase in sphingomyelin, 240\% increase in phosphatidylserine, 290\% in phosphatidylglycerol, $2150 \%$ in lyso-phosphatidylethanolamine) and $1190 \%$ in lyso-phosphatidylchoxline. A great number of membrane lipids were significantly different between prom1-exo and the membrane compartment of parental FEMX-I cells (Table 3). To offset the elevated sphingolipid levels, phosphatidylcholine levels were decreased by $26 \%$, resulting in similar choline-containing lipid levels between prom1-exo and the FEMX-I plasma membrane. A 45\% decrease in phosphatidylinositol content of prom1-exo also partially accounted for the observed increase in raft-associated lipid species of the exosomes.

\section{Specific "loading" of miRNAs in prom1-exo}

The miRNA "cargo" of prom1-exo was significantly different from the parental cell content. Of the 1,058

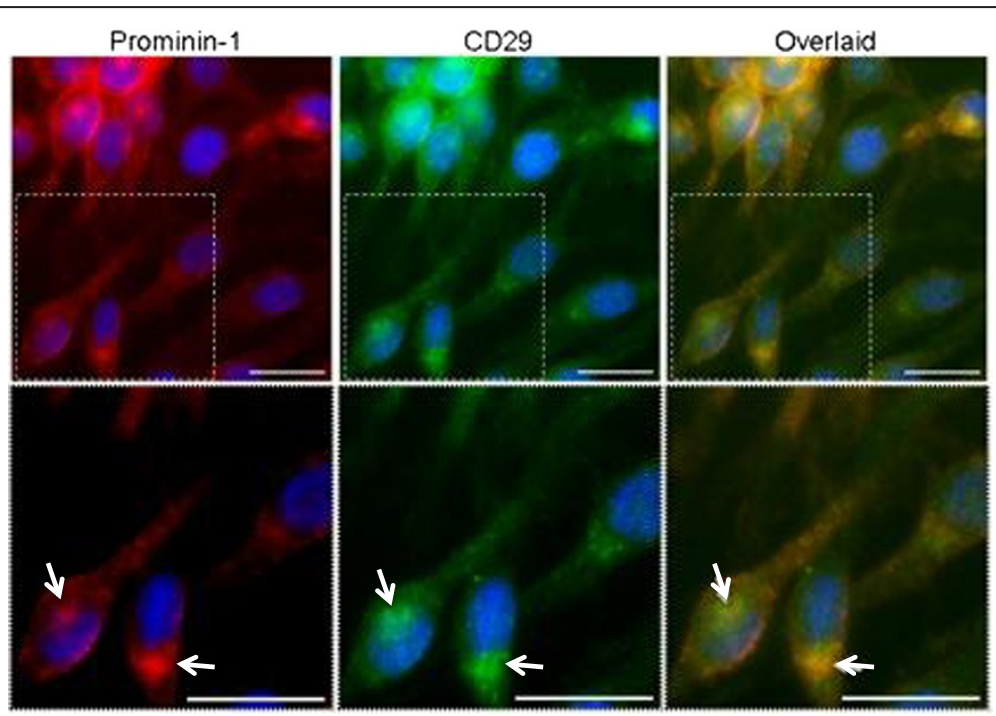

Figure 3 Co-localization of prominin-1 with CD29 in FEMX-I cells. Insets in the upper panels were enlarged in the lower panels. Arrows represent areas of peri-nuclear co-localization of prominin-1 and CD29. Prominin-1, red. CD29, green; DAPI, blue. Bars, $25 \mu \mathrm{m}$. 


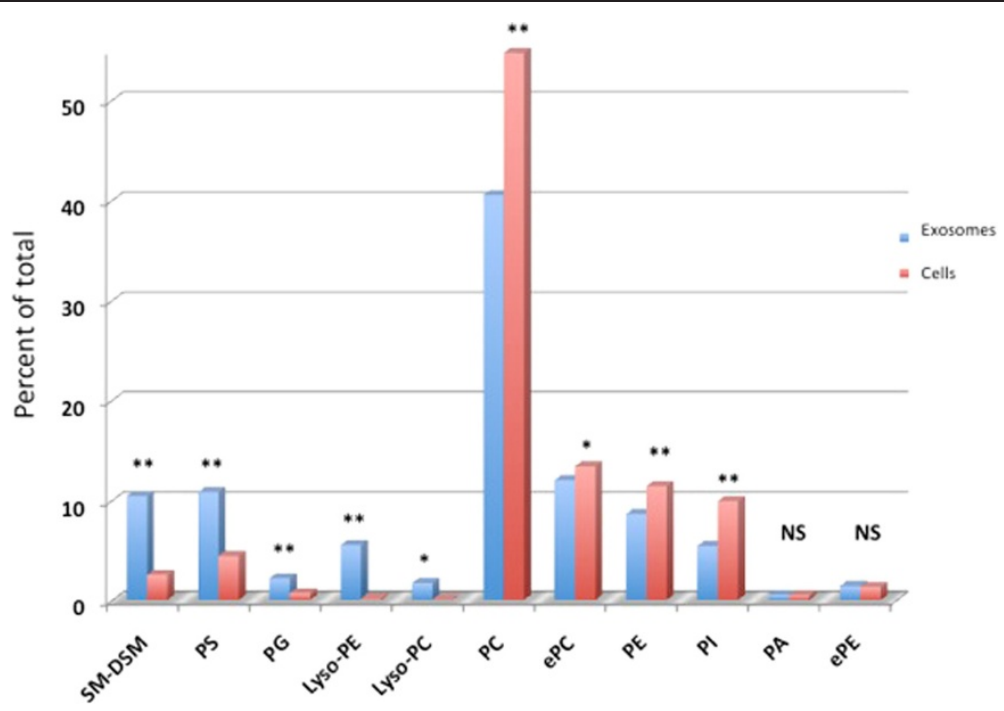

Figure 4 Different membrane lipid distribution between parental FEMX-I cells and prom1-exo. An automated ESI-tandem mass spectrometry approach was used. The lipid extracts from cells and microvesicles were dissolved in $1 \mathrm{ml}$ chloroform. An aliquot of $50 \mu \mathrm{l}$ of each extract in chloroform was used for each analysis. To correct for chemical or instrumental noise in the samples, the molar amount of each lipid metabolite detected in the "internal standards only" spectra was subtracted from the molar amount of each metabolite calculated in each set of sample spectra. The data from each "internal standards only" set of spectra was used to correct the data from the following 10 samples. Finally, the data were corrected for the fraction of the sample analyzed and normalized to the $\mathrm{mg}$ protein to produce data in the units $\mathrm{nmol} / \mathrm{mg}$. Data are presented as percent of total lipids analyzed. *, $p<0.05$; ${ }^{* *}, \mathrm{p}<0.01$ (unpaired Student's $t$ test). SM-DSM, sphingomyelin-dihydro sphingomyelin; PS, phosphatidylserine; PG, phosphatidylglycerol; e-PE, ether-linked phosphatidylethanolamine; e-PC, ether-linked phosphatidylcholine; PI, phosphatidylinositol; PA, phosphatidic acid.

miRNA species investigated, only 49 were overexpressed in prom1-exo (Table 3), including miRNAs known to mediate immune tolerance, and 13 cancer/ metastasis-associated miRNAs. In particular, miR-216b, a well-known tumor and metastasis suppressor miRNA, that targets Ras $[43,44]$, was highly expressed in prom1-exo and undetectable in FEMX-I cells, indicating a detoxification role for prom1-exo; let-7i, associated with metastatic progression [45-47], was found to be expressed at levels 53-fold higher in prom1-exo than in FEMX-I cells. Also, miR-10a, reportedly involved in the metastatic process and immune-escaping $[48,49]$ was 3.2-fold higher in prom1-exo than in parental cells.

\section{Transfer of prom1-exo to adjacent FEMX-I and MSC}

Exposure of FEMX-I cells to PKH-67-labeled prom1-exo for $3 \mathrm{~h}$ resulted in massive green perinuclear fluorescence (Figure 6A), co-localized with the red fluorescence of the intracellular pool of prominin-1 upon incubation of the cells with phycoerythrin-conjugated monoclonals (Figures 6A and 3A-B). Interestingly, also exposure of human MSC to PKH-67-labeled prom1-exo for $3 \mathrm{~h}$ resulted in intra-cellular localization of fluorescent prom1-exo and of prom1-exo-associated prominin-1 (Figure 6A); for MSC, the punctate pattern differed from the perinuclear accumulation for FEMX-I cells, presumably for the lack of an endogenous pool of prominin-1 in MSC. Since a shorter $(1 \mathrm{~h})$-exposure of FEMX-I to PKH-67-labeled prom1-exo resulted in exclusive, although minor, perinuclear accumulation of green fluorescence (data not shown), the complete absence of puncta in FEMX-I cells may be due to the rapid kinetics of intracellular exosome trafficking or turnover. To confirm the intracellular delivery of prominin- 1 by prom1-exo, MSC were incubated with prom1-exo prepared from FEMX-I cells transiently transfected with a prominin-1-GFP fusion plasmid. After $3 \mathrm{~h}$, extensive fluorescence from prominin-1-GFP was detected in the intracellular compartment of MSC (Figure 6B), confirming that prominin-1 was effectively delivered to MSC. To investigate whether direct transfer of prom1exo occurred from FEMX-I to MSC in mixed cultures, we co-cultured the cells at 5:1 ratio (FEMX-I:MSC) for $24 \mathrm{~h}$, and analyzed the expression of prominin- 1 by immunofluorescence. Figure 6 clearly shows transfer of prominin-1 from FEMX-I to the intracellular compartment of MSC. The apparent contrast between the massive uptake of exosomes in Figure 6 and the relatively low transfer of exosomes from FEMX-I to MSC in Figure 7 may be explained by the technical differences of the two experiments (sudden addition of exosomes in Figure 6 and gradual release of exosomes in Figure 7). 


\section{MV vs FEMX}

\begin{tabular}{|c|c|c|c|}
\hline PC 34:1** & PS $34: 1 \leqslant *$ & PE 34:1** & PI $34: 1^{* *}$ \\
\hline PC $34: 2 * *$ & PS 34:2 & PE 34:2*1* & PI 34:2** \\
\hline PC 34:3* & PS 34:3* & PE 34:3*1*⿻二丨 & P1 34:3* \\
\hline PC $36: 1 * * 6$ & PS 36:1** & PE 36:1 & P1 36:1 \\
\hline PC $36: 2^{* *+}$ & PS $36: 2 * 1+1$ & PE 36:2 & PI 36:2** \\
\hline PC $36: 3 * 6$ & PS 36:3 & PE 36:3** & PI 36:3*** \\
\hline PC $36: 4^{*}$ & PS 36:4 & PE 36:4** & PI 36:4 \\
\hline PC 38:0*:* & PS 38:0 & PE 38:0 & PI 38:0 \\
\hline PC 38:1 & PS 38:1* & PE 38:1 & PI 38:1* \\
\hline PC $38: 2$ & PS 38:2k* & PE 38:2 & P1 $38: 2^{* *}$ \\
\hline PC $38: 3^{* *}$ & PS 38: $3^{*}$ & PE 38:3* & PI $38: 3^{* *}$ \\
\hline PC 38:4 & PS 38:4 & PE 38:4** & PI 38:4** \\
\hline PC 38:5 & PS 38:5 & PE 38:5* & PI 38:5* \\
\hline PC 38:6 & PS 38:6 & PE 38:6年米 & PI 38:6 \\
\hline PC 40:2 & PS 40:2** & PE 40:2 & PI $40: 2^{* * * *}$ \\
\hline PC 40:3 & PS 40:3 & PE 40:3 & PI 40:3 \\
\hline PC 40:4 & PS 40:4** & PE 40:4 & PI 40:4 \\
\hline PC 40:5 & PS 40:5 & PE 40:5* & PI 40:5 \\
\hline PC 40:6 & PS 40:6 & PE 40:6 & PI 40:6 \\
\hline PC 40:7 & PS 40:7 & PE 40:7 & PI 40:7 \\
\hline PC 42:5* & PS 42:5 & PE 42:5 & PI 42:5 \\
\hline PC 42:8 & PS 42:8 & PE 42:8 & PI 42:8 \\
\hline \multirow[t]{2}{*}{ PC 42:9 } & PS 42:9 & PE 42:9 & PI 42:9* \\
\hline & & PE 28:0** & \\
\hline PC 28:1 & & PE 28:1 & \\
\hline PC 30:0*+ & & PE 30:0*** & \\
\hline PC 30:1* & & PE 30:1*4* & \\
\hline PC 32:0** & PS 32:0 & PE 32:0* & \\
\hline PC 32:1*** & PS 32:1** & PE 32:1*** & \\
\hline PC 32:2*** & & PE 32:2*** & \\
\hline PC 34:0 & PS 34:0 & & \\
\hline PC 34:4 & & PE 34:4* & PI 34:4 \\
\hline \multirow[t]{2}{*}{ PC 36:0 } & PS 36:0 & PE 36:0 & \\
\hline & PS 36:5 & PE 36:5*** & PI 36:5* \\
\hline \multirow[t]{4}{*}{ PC 36:6 } & & PE 36:6 & PI 36:6*1*4 \\
\hline & PS 38:7** & & \\
\hline & & & PI 40:0 \\
\hline & PS 40:1* & & PI 40:1 \\
\hline PC 40:8 & PS 40:8 & & PI 40:8** \\
\hline PC 42:10 & PS 42:10 & PE 42:10 & \\
\hline PC 42:11. & PS 42:11 & & \\
\hline PC 42:2 & & PE 42:2 & PI 42:2 \\
\hline \multirow{5}{*}{$\begin{array}{l}\text { PC 42:3 } \\
\text { PC } 42: 4\end{array}$} & & PE 42:3 & PI $42: 3^{*}$ \\
\hline & PS 42:6 & PE 42:6** & \\
\hline & PS 42:7 & PE 42:7** & PI 42:7 \\
\hline & PS 44:10 & & PI 44:10 \\
\hline & PS 44:11 & & \\
\hline \multirow[t]{3}{*}{ PC 44:12 } & PS 44:12 & PE 44:12 & \\
\hline & PS 44:2 & PE 44:2 & PI 44:2 \\
\hline & PS 44:3 & PE 44:3* & \\
\hline PC 44:4 & PS 44:4 & PE 44:4 & \\
\hline \multirow[t]{4}{*}{ PC 44:5. } & PS 44:5 & & \\
\hline & PS 44:6 & PE 44:6 & \\
\hline & PS 44:7 & PE 44:7 & PI 44:7 \\
\hline & PS 44:8 & & PI 44:8 \\
\hline PC 44:9 & & PE 44:9 & \\
\hline
\end{tabular}

Figure 5 Differences in lipid profiling between prom1-exo (MV) and parental FEMX-I cells (FEMX). An automated ESI-tandem mass spectrometry approach was used for lipid profiling. Averages of three to five determinations for each sample group were calculated. Red, lipid species over-expressed in prom1-exo; blue, lipid species over-expressed in parental FEMX-I cells. ${ }^{*}, p<0.05$; ${ }^{* *}, p<0.01$; ${ }^{* *}$ $p<0.001$ (unpaired Student's t test); head groups: PS, phosphatidyl serine; $\mathrm{PE}$, phosphatidylethanolamine; $\mathrm{PC}$, phosphatidylcholine; $\mathrm{PI}$, phosphatidylinositol; the first number indicates the length of the hydrocarbon chain and the second number indicates the number of double bonds.

\section{Effects of exosomes on MSC invasiveness}

We then investigated whether exposure of MSC to prom1-exo resulted in biological effects, such as changes in their invasiveness, measured by the capacity of MSC to pass through a Matrigel layer. Interestingly, a 90\% increase in Matrigel invasion was observed after a standard $24 \mathrm{~h}-$ assay, compared with mock-treated MSC (Figure 8).

\section{Discussion}

Building on our previous finding of a pro-metastatic role of prominin-1 in melanoma [9], we have here isolated from in vitro serum-free cultures of FEMX-I melanoma prominin-1-expressing exosomes. This is the first report of prominin-1-based purification of cancer exosomes. The prominin-1-based exosomal isolation protocol was then successfully employed to isolate exosomes from the serum-free culture medium of another prominin-1-expressing cancer cell line, Caco-2 colon carcinoma. Interestingly, Tauro et al. [50] recently reported the isolation, via sequential immunocapture using anti-A33- and anti-EpCAM-coupled magnetic beads, of prominin-1-expressing exosomes from the human colon carcinoma cell line LIM1863.

Consistent with findings of other groups in different experimental models [51,52], a specific sorting of proteins, lipids and microRNA was observed in in prom1exo. Preparations of exosomes from biological fluids and in vitro cell cultures using a variety of strategies and techniques have been extensively reported by many groups; however, the great majority of preparations contain varying proportions of other membranous vesicles that co-purify with exosomes, such as shed microvesicles and apoptotic blebs $[8,33]$. The importance of analyzing purified exosomal preparations is evident if we consider that although exosomes, due to their small size (40-100 $\mathrm{nm})$, are expected to contain less than 150 proteins, to date over 4,500 proteins have been identified in exosomes from multiple organisms (http://exocarta.org). While some of these proteins are considered tissuespecific, many can be considered preparation contaminants. The fact that prom1-exo present respectively a 78- and 168-fold higher concentration of prominin-1 
Table 3 List of miRNAs over-expressed in prom1-exo compared with parental FEMX-I cells

\begin{tabular}{|c|c|c|c|c|}
\hline miRNA & Ct FEMX-Cells & $\begin{array}{l}\text { Ct FEMX- } \\
\text { Exosomes }\end{array}$ & $\mathrm{DCt}$ & Fold-charge \\
\hline hsa-miR-216b & $>40$ & 15.81 & 24.2 & 19138839.3 \\
\hline hsa-miR-889 & 37.33 & 15.86 & 21.47 & 2910427.1 \\
\hline hsa-miR-4307 & $>40$ & 22.51 & 17.5 & 184083.4 \\
\hline hsa-miR-4272 & $>40$ & 22.99 & 17 & 131983.7 \\
\hline hsa-miR-203 & $>40 \mathrm{cyclcs}$ & 23.82 & 16.2 & 74244.7 \\
\hline hsa-miR-4289 & 23.34 & 8.67 & 14.66 & 25944.3 \\
\hline hsa-miR-3149 & 22,7 & 8.77 & 13.94 & 15746.0 \\
\hline hsa-miR-203 & 26.41 & 13.69 & 12.72 & 6769.4 \\
\hline hsa-miR-3145 & 21.19 & 10.53 & 10.66 & 1622.1 \\
\hline hsa-miR-1911 & $>40$ & 29.72 & 10.3 & 1243.3 \\
\hline hsa-miR-513a-3p & $>40$ & 29.84 & 10.2 & 1144.1 \\
\hline hsa-miR-3916 & $>40$ & 30.52 & 9.48 & 714.1 \\
\hline hsa-miR-886-3p & $>40$ & 32.31 & 7.69 & 206.5 \\
\hline hsa-miR-1182 & 22.77 & 15.91 & 6.86 & 115.1 \\
\hline hsa-miR-3613-5p & $>40$ & 33.69 & 6.31 & 79.3 \\
\hline hsa-let-7i & 22.95 & 17.21 & 5.73 & 53.2 \\
\hline hsa-miR-3132 & 16.50 & 11.49 & 5.01 & 32.2 \\
\hline hsa-miR-3914 & 24.75 & 20.39 & 4.36 & 20.5 \\
\hline hsa-miR-3618 & 28.56 & 24.35 & 4.21 & 18.5 \\
\hline hsa-miR-1307 & 21.87 & 17.96 & 3.91 & 15.0 \\
\hline hsa-miR-3614-3p & 21.90 & 19.15 & 2.75 & 6.7 \\
\hline hsa-miR-519c-3p & 22.59 & 20.22 & $2.3 k$ & 5.2 \\
\hline hsa-miR-3160 & 17,61 & 15.28 & 2.33 & 5.0 \\
\hline hsa-miR-3153 & 11.48 & 9.53 & 1.96 & 3.9 \\
\hline hsa-miR-4278 & 18.94 & 16.99 & 1.95 & 3.9 \\
\hline hsa-miR-3646 & 1.58 & 15.80 & 1.79 & 3.5 \\
\hline hsa-miR-3926 & 17.47 & 15.72 & 1.75 & 3.4 \\
\hline hsa-miR-515-5p & 28.37 & 26.69 & 1.68 & 3.2 \\
\hline hsa-miR-3169 & 14.33 & 12.67 & 1.66 & 1.2 \\
\hline hsa-miR-10a & 31.87 & 30.21 & 1.66 & 3.2 \\
\hline hsa-miR-140-5p & 26.92 & 25.37 & 1.55 & 2.9 \\
\hline hsa-miR-3148 & 18.74 & 17.56 & 1.18 & 2.3 \\
\hline hsa-miR-4271 & 17.56 & 16.48 & 1.08 & 2.1 \\
\hline hsa-miR-627 & 23.07 & 22.00 & 1.07 & 2.1 \\
\hline hsa-miR-548d-3p & 29.69 & 28.66 & 1.03 & 2.0 \\
\hline hsa-miR-3613-3p & 22.09 & 21.19 & 0.90 & 1.9 \\
\hline hsa-miR-481 & 26.49 & 25.64 & 0.85 & 1.8 \\
\hline hsa-miR-571 & 20.81 & 19.97 & 0.84 & 1.8 \\
\hline hsa-miR-4274 & 19.93 & 19.15 & 0.79 & 1.7 \\
\hline hsa-miR-4277 & 21.41 & 20.79 & 0.62 & 1.5 \\
\hline hsa-miR-3686 & 15.41 & 14.81 & 0.61 & 1.5 \\
\hline hsa-miR-3074 & 21.65 & 21.10 & 0.54 & 1.5 \\
\hline hsa-miR-95 & 24.90 & 24.45 & 0.46 & 1.4 \\
\hline
\end{tabular}

Table 3 List of miRNAs over-expressed in prom1-exo compared with parental FEMX-I cells (Continued)

\begin{tabular}{|c|c|c|c|c|}
\hline hsa-miR-590-3p & 26.81 & 26.49 & 0.32 & 1.2 \\
\hline hsa-miR-525-5p & 23.20 & 22.90 & 0.30 & 1.2 \\
\hline hsa-miR-548g & 26.97 & 26.69 & 0.28 & 1.2 \\
\hline hsa-miR-365 & 25.46 & 25.18 & 0.28 & 1.2 \\
\hline hsa-miR-525-3p & 23.23 & 22.94 & 0.28 & 1.2 \\
\hline hsa-miR-320d & 21.97 & 21.93 & 0.04 & 1.0 \\
\hline \multicolumn{5}{|c|}{$\begin{array}{l}\text { Total RNA from FEMX-I cells and exosomes was prepared with Qiazol } \\
\text { extraction followed by poly-A tailing reactions and miRNA CDNA synthesis. } 250 \\
\text { ng of cell's total RNA and of exosomes' RNA were used in CDNA synthesis. } \\
\text { cDNA synthesis were carried out simultaneously and equal volume of CDNA } \\
\text { synthesis reaction product was used in the subsequent real-time qPCR } \\
\text { reactions. } 1058 \text { miRNAs were investigated. The DeltaCt (DCt) values for each } \\
\text { miRNA-specific prom1-exo cDNA greater than } 0.01 \text { were listed. }\end{array}$} \\
\hline
\end{tabular}

and alix compared with microvesicles derived from the same cell line, as well a striking concentration of certain classes of microRNA, indicates that prom1-exo constitute an homogeneous species of exosomes, loaded with a pro-metastatic cargo.

It is now becoming clear that, when a complex message needs to be sent to surrounding cells in the microenvironment, cells use exosomes, which have the advantage, compared to other means of intercellular communication, to target multiple specific locations inside the target cell(s), based, at least in part, on the specific Rab proteins expressed, which act as mailing tags to distribute exosomes to the correct intracellular compartment. The presence of 5 distinct Rabs (Rab 5B, Rab 5C, Rab 7A, Rab 8A and Rab 10) suggests that prom1exo are destined to different endosomal compartments in the host/target cell. For example, Rab 5C, 7A and 8A are indispensable effectors/constituents of early endosomes, late endosomes, and secretory endosomes, respectively $[53,54]$. Herein, we have clearly shown rapid uptake of prom1-exo into neighboring FEMX-I cells and MSC, associated with intracellular delivery of prominin-1. Our finding that prom1-exo contain proteins involved in the ESCRT complex suggests that, once they reach their target cell(s), prom1-exo are able to be endocytosed into the endosomal system of recipient cells and deliver their "cargo" into the cytoplasm as a reversal mechanism of their formation process. Interestingly, the presence in prom1-exo of the "fusogenic" proteins CD9, CD63, CD81, ADAM 10, GTP-binding protein $\alpha 13$ and RhoA [55-59] suggests also an alternative mechanism of "cargo" delivery, i.e. receptormediated fusion with the plasma membrane of the host cell(s).

The presence of both syntenin-1 and alix in prom1exo supports a recent theory of the biogenesis of intraluminal vesicles (ILVs) and exosomes [60], while the presence of two heat shock proteins, hsp70 and hsc70 


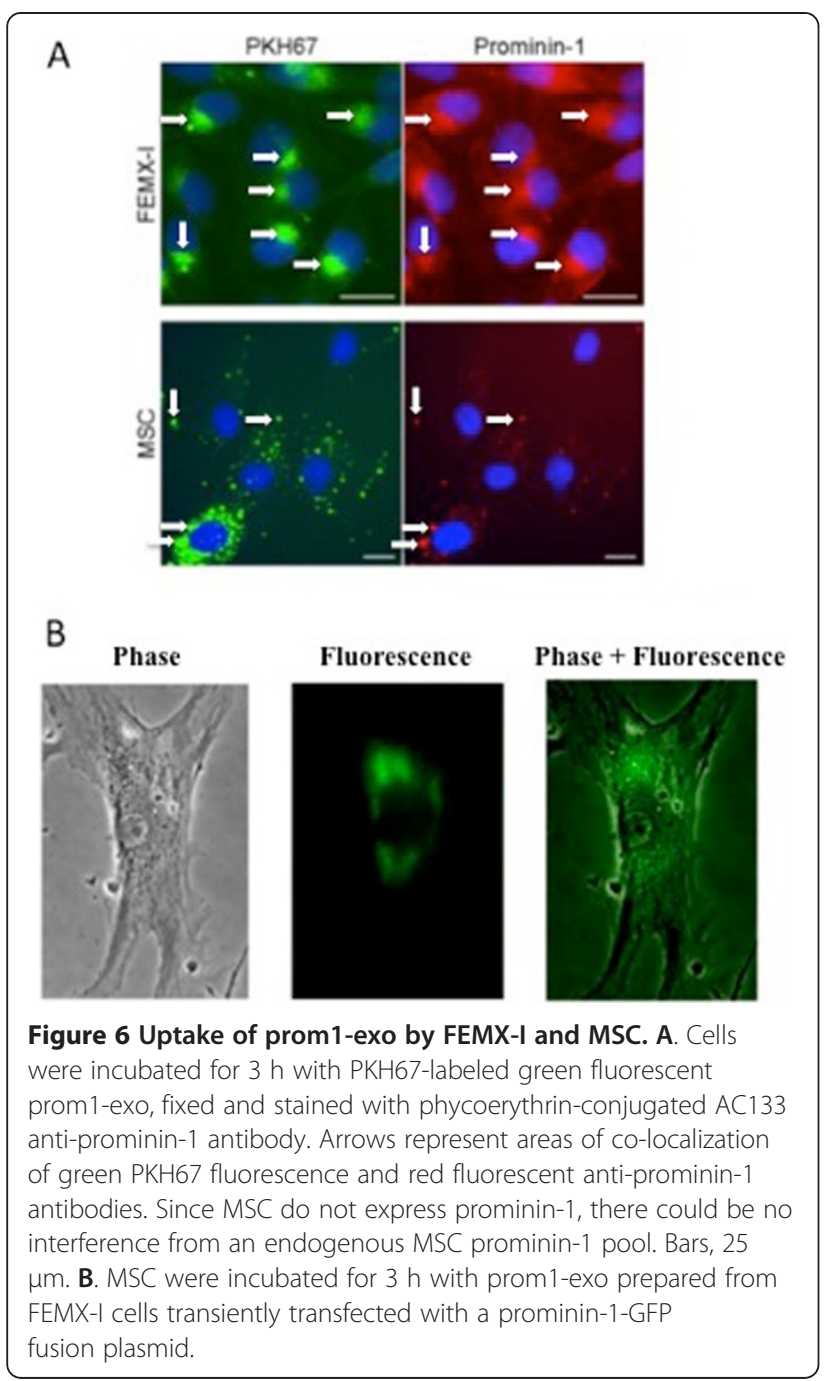

and of the hsc-70 co-chaperone dj2 [61] is in agreement with their function in endosomal cargo selection and in general as molecular chaperones, limiting protein aggregation, and facilitating protein refolding. Our data are consistent with the previous finding of secretion of heat shock proteins into the circulation via lipid raft-mediated, or exosome-mediated exocytosis in tumor cells [62]. Interestingly, the high level of expression of IgSF8, known to have an immunosuppressor role, by inhibiting T-cell mobility coordinately with CD81 [63], and the finding by other groups that extracellular HSPs exert immunomodulatory activities [62] suggest an important role of prom1-exo in the immune escape of FEMX-I melanoma.

Several tetraspanins were identified in prom1-exo. Many members of the tetraspanin family, the most abundant protein family found in exosomes [33], including most of the tetraspanins present in prom1-exo, regulate cell migration, fusion, and signaling events by their recruitment into special membrane microdomains and their abundant presence in microvesicles that mediate intercellular communication [64]. Interestingly, tetraspanins organize other proteins through intra- and intermolecular interactions into a multimolecular tetraspanin enriched microdomains (TEMs), which, in association with other proteins and lipids, such as cholesterol and sphingomyelin [65], forms the extended network of tetraspanin interactions in the membrane, commonly described as tetraspanin web [66]. Our findings of coexpression of many tetraspanins and of a 4-fold increase in sphingomyelin supports the concept that tetraspanin webs are building blocks of prom1-exo.

By ESI/MS-MS lipid profiling, we found that typical raft components were associated with prom1-exo. The fact that other cancer cell types secrete exosomes containing similarly organized lipid subdomains [51,67], suggests that lipid rafts may play a general role in exosome biogenesis and structure, especially sphingolipids, known to play a key role in the genesis of exosomal MVBs [68], and phosphoglycerides with long and saturated fatty-acyl chains [67-69]. Our data also support the hypothesis that the lipid raft composition of endosomes, of which exosomes represent an extracellular mirror, allows them to be multi-purpose platforms [70].

As proposed for hematopoietic and neural stem cells [71,72], prominin-1 may have a specific role in intercellular communication via exosomes, and protein-lipid assemblies might be the essential structural determinant in the release process of prominin-1 by stem and cancer stem cells. In addition, the full molecular characterization of prom1-exo described here supports the concept of 'cancer stem cell-specific lipid rafts' holding molecular determinants necessary to maintain cancer stem cell/ pro-metastatic properties [72]. Interestingly, the high sphingomyelin and phosphatidylserine content of prom1exo may lead to their capacity to fuse with the plasma membrane of host cells and enter the intracellular compartment [32]. In fact, lipid rafts reportedly [73] affect protein binding and modulate membrane physicochemical and mechanical properties: thus, sphingomyelinenriched microdomains modulated the efficiency of membrane fusion [74], and annexin V blockade of phosphatidylserine on the surface of exosomes prevented exosome uptake into microglia [75].

The 21.5-fold increase in lyso-phosphatidylethanolamine observed in prom1-exo may contribute to the pro-metastatic phenotype of FEMX-I cells, in light of the report by Park et al. [76] that lyso-phosphatidylethanolamine treatment of SK-OV3 ovarian cancer cells results in chemotactic migration and cellular invasion. However, whether this mechanism or the transfer of metalloproteinases, such as ADAM10, present in prom1-exo, is responsible for the increased invasiveness 

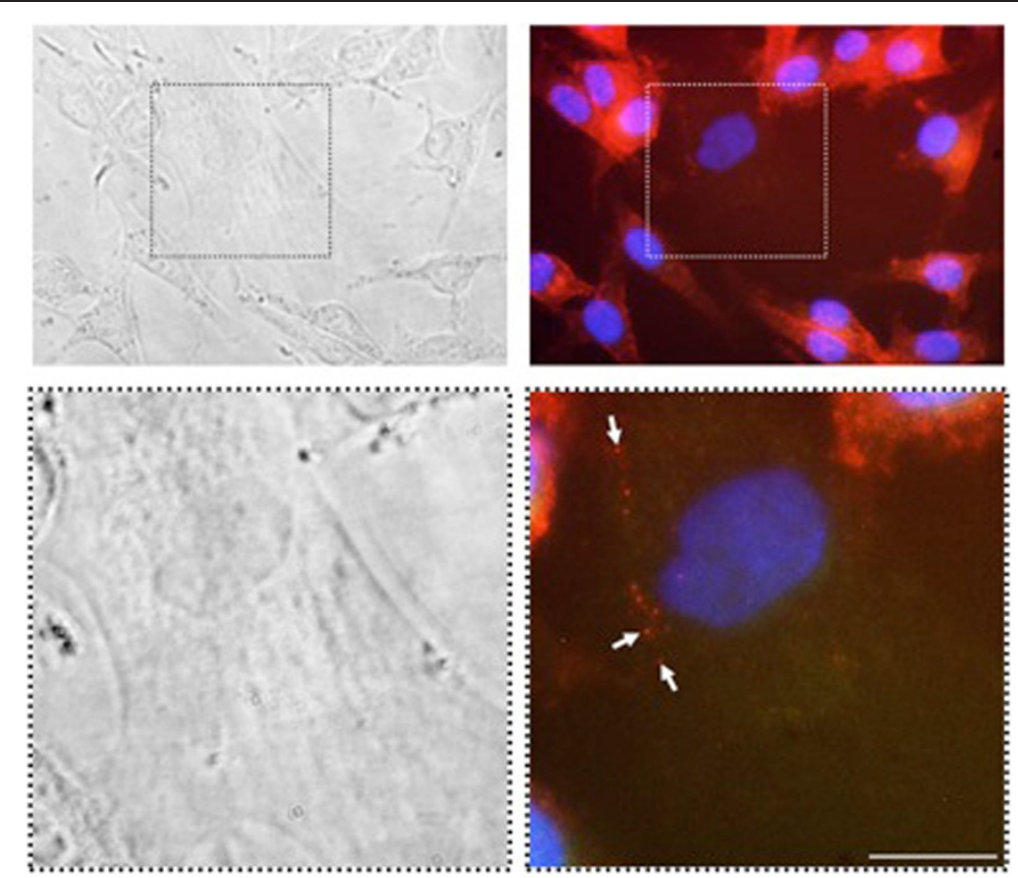

Figure 7 Co-culture of MSC and FEMX-I cells shows uptake of prominin-1 by MSC. MSC and FEMX-I cells were cultured for $24 \mathrm{~h}$ at 1:5 ratio. After fixation and permeabilization, expression of prominin-1 was analyzed by immunofluorescence employing phycoerythrin-conjugated AC133 anti-prominin-1 antibody. Since MSC do not express prominin-1, there could be no interference from an endogenous MSC prominin-1 pool. Insets in the upper panels were enlarged in the lower panels. Arrows indicate some areas of prominin-1 positivity inside a MSC. Red, prominin-1; blue, DAPI. Bars, $25 \mu \mathrm{m}$.

of MSC upon exposure to prom1-exo can not be concluded from the present study.

Consistent with other previous studies [77-79], a considerable difference in the miRNA profile of cancer exosomes and the originating cancer cells was observed in the present study. Specifically, 49 miRNA were found to be over-expressed in prom1-exo, including miRNAs known to mediate immune tolerance, and 13 cancer/metastasis-associated miRNAs. This is in apparent contrast with the claim from several authors $[80,81]$ that the miRNA content of circulating exosomes is similar to that of the originating cancer cells. The cancerassociated loss of miRNA expression often leads to a proliferative advantage and aggressive behavior through largely unknown mechanisms. The finding of very high levels of miR-216b in prom1-exo, coupled with undetectable levels in parental FEMX-I cells, is intriguing in light of reports that miR-216b suppresses tumor growth and invasion by targeting KRAS in nasopharyngeal carcinoma [43] and inhibits cell proliferation and colony formation through Ras inhibition in a pancreatic cancer model [44]. Similarly, a 53-fold lower level of let-7i was observed in FEMX-I cells compared with prom1-exo. Since underexpression of let-7i was found to characterize metastatic progression of oral carcinoma [45] and to have a crucial role in colorectal cancer metastasis [46], it is conceivable that exosomal removal of both miR-216b and let-7i from the intracellular compartment plays a significant role in the malignant phenotype of FEMX-I melanoma. While removal of some species of microRNAs may have a detoxification role, exosomal delivery of other species of microRNA, such as miR-10a, to other cells in the microenvironment may play an important role in FEMX-I melanoma immunoescape. In fact, miR-10a, present in prom1-exo at levels 3.2-fold higher than in parental cells, was recently shown to attenuate the phenotypic conversion of inducible $\mathrm{T}$ (reg) cells into follicular helper T cells and limit differentiation into the $\mathrm{T}(\mathrm{H}) 17$ subset of helper $\mathrm{T}$ cells [48]. Also, miR-10a reportedly stimulates cell invasion, suggesting a potential mechanism for the pro-invasive effect of prom1-exo on MSC [49]. Therefore, prom1-exo may accomplish for FEMX-I melanoma cells a double role of cell detoxification via excretion and of modulation of the function of other cell types, in particular $\mathrm{MSC}$, in the microenvironment. Our data, suggesting a pro-malignant role of prom1-exo, are consistent with a recent report by Peinado et al. [7] that exosomes from highly metastatic melanomas increased the metastatic behavior of primary tumors by permanently 'educating' bone marrow progenitors through the receptor tyrosine kinase MET. To metastasize, tumor cells need to send 


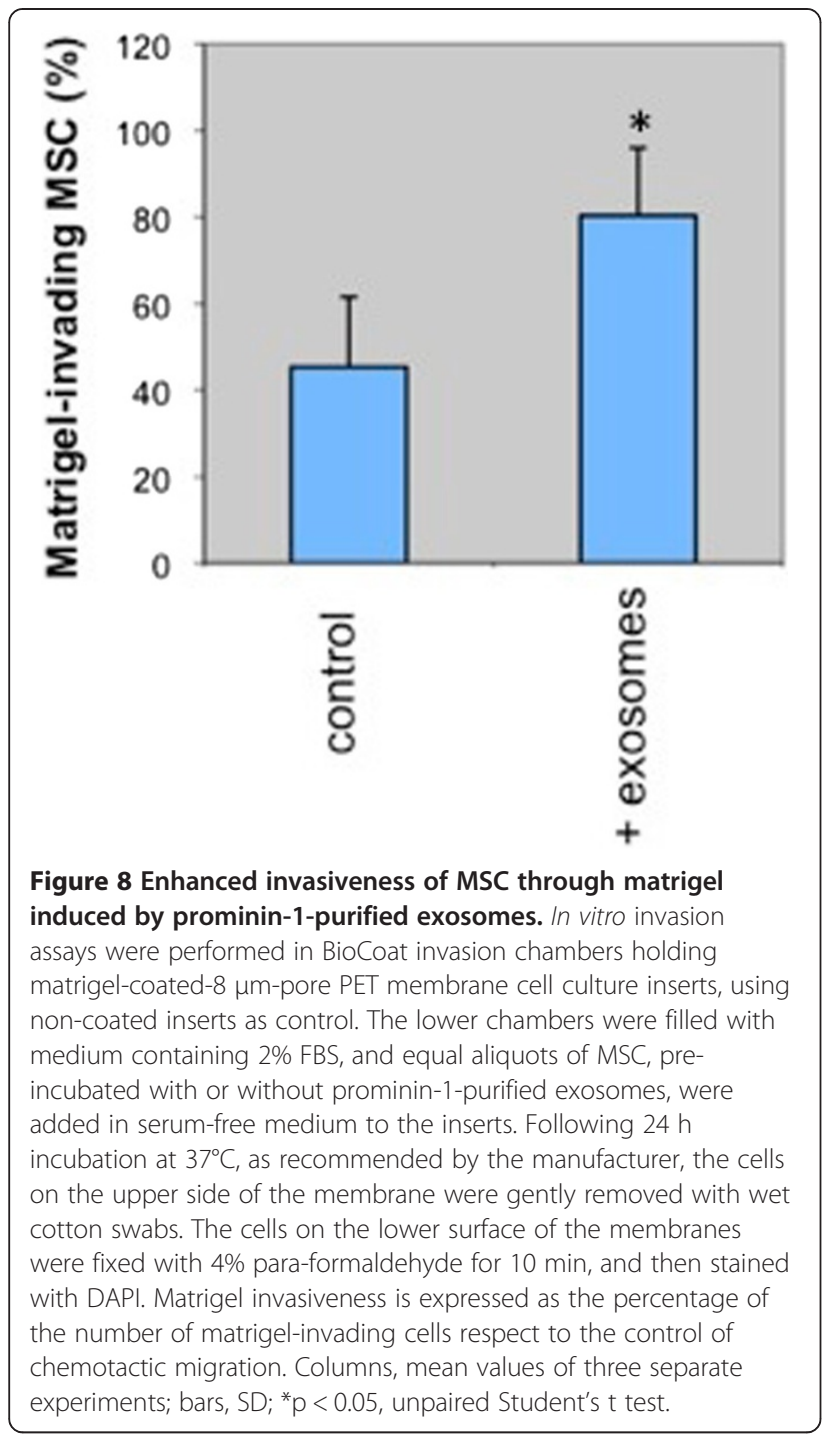

complex messages intended to subvert the normal function of their immediate neighbors, fertilize vasculogenesis and find or recruit a susceptible berth. However, messages of all sorts are being identified in many functional exosomal studies, and if we sample them stochastically it will be difficult to see the whole picture. Prom1-exo, homogenous cancer organelles expressing a cancer stem cell marker, are more likely to have a concordant message(s), and this makes them especially interesting to gain insight into the mechanisms by which exosomes contribute to the malignant phenotype. In addition, our characterization of prom1-exo from FEMX-I cells may be employed as a model for investigating the rules that govern the formation of membrane microdomains: in contrast to rafts, exosomes are remarkably stable structures that can be purified without the intervention of destructive techniques such as detergents or ultrasounds. Our model, therefore, in addition to allowing progress in the understanding of the role(s) of cancer-derived exosomes in the metastatic process, can also shed light on the natural process of selective proteolipidic sorting in biological membranes and trafficking in living cells. Further studies are warranted to determine what part of their cargo and which molecular mechanisms exosomes, and in particular prom1-exo, utilize to modify the phenotype of the different cells in the local tumor microenvironment and exert specific roles in the metastatic phenotype.

\section{Additional files}

Additional file 1: Table S1. Search conditions for proteomic LC-MS/MS data sets. MS/S data was acquired during 70 min gradients run on handpacked capillary columns as described in Materials and Methods. The effluent was interfaced to an ESI source and peptides were recorded with data-dependent scanning using a top 5 method on an LTQ/XL ion trap (Thermo). Table 1 describes data processing, search conditions common to both the MASCOT and Spectrum Mill Proteomics Workbench applied in this work as well as particular features of the SwissProt database used.

Additional file 2: Table S2. Protein assignments. Use of the Peptide and Protein Prophet algorithms to condense independent searches of the same data sets provided 282 proteins (including keratins) across a total of three biological isolations of prom1-exo with an FDR of $0.1 \%$, a minimum of three peptides and a protein sensitivity of $99 \%$. Additional file 2 lists proteins matching these criteria.

Additional file 3: Table S3. All Peptides attributed to proteins from Additional file 2. All peptides identified in three replicate isolations of prom1-exo. Scaffold 4.0.0 was used to rescore the results of MASCOT and SpectrumMill searches. Scaffold generates an adaptive discriminate scoring using Peptide and Protein Prophet algorithms. Complete results are listed in Additional file 3: Table S3.

Additional file 4: Table S4. Selection of the most observable proteins associated with prom1-exo. Tables 1 and 2 of the manuscript illustrate protein enrichment for physiological processes involving endosome and ESCRT complexes. These proteins are highlighted among an ensemble verified with two or more stringent peptide spectral matches (PSM) in all three replicates or those observed with three or more stringent PSM in any two replicates. Additional file 4: Table $\$ 4$ is a complete list of these 154 proteins.

Additional file 5: Figure S1. Enrichment for physiological processes of the most observable proteins associated with prom1-exo.

\section{Abbreviation \\ Prom1-exo: Prominin-1-expressing exosomes; MSC: Bone marrow-derived stromal cells; NTA: Nanoparticle tracking analysis; ESI: Electrospray ionization; TEM: Tetraspanin enriched microdomain; MVB: Multivesicular body; VPS: Vacuolar protein sorting; ESCRT: Endosomal sorting complex required for transport.}

\section{Competing interests}

The authors declare that they have no competing interests.

\section{Authors' contributions}

GR and AL designed and executed most of the experiments and wrote the manuscript. JM analyzed proteins by Western blotting and performed the invasion assays. FA prepared microvesicles and exosomes. RMP analyzed proteins by mass spectrometry, wrote the proteomics part of the manuscript and helped writing the manuscript. All authors read and approved the final manuscript. 


\section{Acknowledgements}

We thank Harry Rosenberg, Renee Coffman and Ronald R. Fiscus for their support and encouragement; Gerd Schmitz and Tatiana Konovalova for advice on the interpretation and statistical analysis of lipidome data; Robert Piper and Giuseppe Pizzorno for reviewing the manuscript; Thuc (Tim) Le for helpful advice; Darwin Prockop for human MSC through grant \# P40RR017447 from NCRR of the US NIH; and Duncan Griffiths of Nanosight for assistance with the exosome counting and analysis. Lipid analysis was performed at the Kansas Lipidomics Research Center, supported by NSF grants MCB 0455318, 0920663, DBI 0521587, and EPS-0236913 with matching support from the State of Kansas through Kansas Technology Enterprise Corporation and Kansas State University, and by K-INBRE (NIH Grant P20 RR16475). Mass spectrometry analysis was performed in the Roy J. Carver Charitable Trust-supported CCOM Proteomics Facility at the University of lowa.

\section{Author details}

'Cancer Research Center, Roseman University of Health Sciences, Las Vegas, NV 89135, USA. ${ }^{2}$ Department of Medical Administration, University of lowa Carver College of Medicine, lowa City, lowa, USA.

Received: 2 April 2013 Accepted: 5 June 2013

Published: 14 June 2013

\section{References}

1. Jemal A, Siegel R, Xu J, Ward E: Cancer statistics. CA Cancer J Clin 2010, 60:277-300

2. Thery C, Zitvogel L, Amigorena S: Exosomes: composition, biogenesis and function. Nat Rev Immunol 2002, 2:569-579.

3. Peinado H, Lavotshkin S, Lyden D: The secreted factors responsible for pre-metastatic niche formation: old sayings and new thoughts. Semin Cancer Biol 2011, 21:139-146.

4. Hood JL, San RS, Wickline SA: Exosomes released by melanoma cells prepare sentinel lymph nodes for tumor metastasis. Cancer Res 2011, 71:3792-3801

5. Jung T, Castellana D, Klingbeil P, Cuesta Hernandez I, Vitacolonna M, Orlicky DJ, Roffler SR, Brodt P, Zoller M: CD44v6 dependence of premetastatic niche preparation by exosomes. Neoplasia 2009, 11:1093-1105.

6. Valadi H, Ekstrom K, Bossios A, Sjostrand M, Lee JJ, Lotvall JO: Exosomemediated transfer of mRNAs and microRNAs is a novel mechanism of genetic exchange between cells. Nat Cell Biol 2007, 9:654-659.

7. Peinado H, Aleckovic M, Lavotshkin S, Matei I, Costa-Silva B, Moreno-Bueno G, Hergueta-Redondo M, Williams C, Garcia-Santos G, Ghajar C, Nitadori-Hoshino A, Hoffman C, Badal K, Garcia BA, Callahan MK, Yuan J, Martins VR, Skog J, Kaplan RN, Brady MS, Wolchok JD, Chapman PB, Kang Y, Bromberg J, Lyden D: Melanoma exosomes educate bone marrow progenitor cells toward a prometastatic phenotype through MET. Nat Med 2012, 18:883-891.

8. Tauro BJ, Greening DW, Mathias RA, Ji H, Mathivanan S, Scott AM, Simpson $\mathrm{RJ}$ : Comparison of ultracentrifugation, density gradient separation, and immunoaffinity capture methods for isolating human colon cancer cell line LIM1863-derived exosomes. Methods 2012, 56:293-304.

9. Rappa G, Mercapide J, Anzanello F, Le M, T T, Johlfs MG, Fiscus RR, Wilsch-Brauninger M, Corbeil D, Lorico A: Wnt interaction and extracellular release of prominin-1/CD133 in human malignant melanoma cells. Exp Cell Res 2013, 319:810-819.

10. Rappa G, Fodstad O, Lorico A: The stem cell-associated antigen CD133 (Prominin-1) is a molecular therapeutic target for metastatic melanoma. Stem Cells 2008, 26:3008-3017.

11. Weigmann A, Corbeil D, Hellwig A, Huttner WB: Prominin, a novel microvilli-specific polytopic membrane protein of the apical surface of epithelial cells, is targeted to plasmalemmal protrusions of non-epithelial cells. Proc Natl Acad Sci USA 1997, 94:12425-12430

12. Yin AH, Miraglia S, Zanjani ED, Almeida-Porada G, Ogawa M, Leary AG, Olweus J, Kearney J, Buck DW: AC133, a novel marker for human hematopoietic stem and progenitor cells. Blood 1997, 90:5002-5012.

13. Klein WM, Wu BP, Zhao S, Wu H, Klein-Szanto AJ, Tahan SR: Increased expression of stem cell markers in malignant melanoma. Mod Pathol 2007, 20:102-107.

14. Frank NY, Margaryan A, Huang Y, Schatton T, Waaga-Gasser AM, Gasser M, Sayegh MH, Sadee W, Frank MH: ABCB5-mediated doxorubicin transport and chemoresistance in human malignant melanoma. Cancer Res 2005, 65:4320-4333
15. Monzani E, Facchetti F, Galmozzi E, Corsini E, Benetti A, Cavazzin C, Gritti A, Piccinini A, Porro D, Santinami M, Invernici G, Parati E, Alessandri G, La Porta CA: Melanoma contains CD133 and ABCG2 positive cells with enhanced tumourigenic potential. Eur J Cancer 2007, 43:935-946.

16. Lorico A, Mercapide J, Rappa G: Prominin-1 (CD133) and Metastatic Melanoma: Current Knowledge and Therapeutic Perspectives. Adv Exp Med Biol 2013, 777:197-211.

17. Fodstad O, Kjonniksen I, Aamdal S, Nesland JM, Boyd MR, Pihl A: Extrapulmonary, tissue-specific metastasis formation in nude mice injected with FEMX-I human melanoma cells. Cancer Res 1988, 48:4382-4388

18. Larson BL, Ylostalo J, Prockop DJ: Human multipotent stromal cells undergo sharp transition from division to development in culture. Stem Cells 2008, 26:193-201.

19. Giebel B, Corbeil D, Beckmann J, Hohn J, Freund D, Giesen K, Fischer J, Kogler G, Wernet P: Segregation of lipid raft markers including CD133 in polarized human hematopoietic stem and progenitor cells. Blood 2004, 104:2332-2338.

20. Shevchenko A, Tomas H, Havlis J, Olsen JV, Mann M: In-gel digestion for mass spectrometric characterization of proteins and proteomes. Nat Protoc 2006, 1:2856-2860.

21. Rappsilber J, Mann M, Ishihama Y: Protocol for micro-purification, enrichment, pre-fractionation and storage of peptides for proteomics using StageTips. Nat Protoc 2007, 2:1896-1906.

22. Keller A, Nesvizhskii Al, Kolker E, Aebersold R: Empirical statistical model to estimate the accuracy of peptide identifications made by MS/MS and database search. Anal Chem 2002, 74:5383-5392.

23. Nesvizhskii Al, Keller A, Kolker E, Aebersold R: A statistical model for identifying proteins by tandem mass spectrometry. Anal Chem 2003, 75:4646-4658

24. Tabb DL, Friedman DB, Ham AJ: Verification of automated peptide identifications from proteomic tandem mass spectra. Nat Protoc 2006, 1:2213-2222.

25. Elias JE, Gygi SP: Target-decoy search strategy for mass spectrometrybased proteomics. Methods Mol Biol 2010, 604:55-71.

26. Elias JE, Gygi SP: Target-decoy search strategy for increased confidence in large-scale protein identifications by mass spectrometry. Nat Methods 2007, 4:207-214

27. Brugger B, Erben G, Sandhoff R, Wieland FT, Lehmann WD: Quantitative analysis of biological membrane lipids at the low picomole level by nano-electrospray ionization tandem mass spectrometry. Proc Natl Acad Sci USA 1997, 94:2339-2344.

28. Devaiah SP, Roth MR, Baughman E, Li M, Tamura P, Jeannotte R, Welti R, Wang X: Quantitative profiling of polar glycerolipid species from organs of wild-type Arabidopsis and a phospholipase Dalpha1 knockout mutant. Phytochemistry 2006, 67:1907-1924.

29. Welti R, Li W, Li M, Sang Y, Biesiada H, Zhou HE, Rajashekar CB, Williams TD, Wang $X$ : Profiling membrane lipids in plant stress responses. Role of phospholipase D alpha in freezing-induced lipid changes in Arabidopsis. J Biol Chem 2002, 277:31994-32002.

30. Liebisch G, Lieser B, Rathenberg J, Drobnik W, Schmitz G: Highthroughput quantification of phosphatidylcholine and sphingomyelin by electrospray ionization tandem mass spectrometry coupled with isotope correction algorithm. Biochim Biophys Acta 2004, 1686:108-117.

31. Lugini L, Matarrese P, Tinari A, Lozupone F, Federici C, lessi E, Gentile M, Luciani F, Parmiani G, Rivoltini L, Malorni W, Fais S: Cannibalism of live lymphocytes by human metastatic but not primary melanoma cells. Cancer Res 2006, 66:3629-3638.

32. Parolini I, Federici C, Raggi C, Lugini L, Palleschi S, De Milito A, Coscia C, lessi E, Logozzi M, Molinari A, Colone M, Tatti M, Sargiacomo M, Fais S: Microenvironmental pH is a key factor for exosome traffic in tumor cells. J Biol Chem 2009, 284:34211-34222.

33. Mathivanan S, Fahner CJ, Reid GE, Simpson RJ: ExoCarta 2012: database of exosomal proteins, RNA and lipids. Nucleic Acids Res 2012, 40:D1241-1244.

34. Gill DJ, Teo H, Sun J, Perisic O, Veprintsev DB, Emr SD, Williams RL: Structural insight into the ESCRT-I/-II link and its role in MVB trafficking. EMBO J 2007, 26:600-612.

35. Misra S, Heldin P, Hascall VC, Karamanos NK, Skandalis SS, Markwald RR, Ghatak S: Hyaluronan-CD44 interactions as potential targets for cancer therapy. FEBS J 2011, 278:1429-1443. 
36. Boroughs LK, Antonyak MA, Johnson JL, Cerione RA: A unique role for heat shock protein 70 and its binding partner tissue transglutaminase in cancer cell migration. J Biol Chem 2011, 286:37094-37107.

37. Inokuchi J, Narula N, Yee DS, Skarecky DW, Lau A, Ornstein DK, Tyson DR: Annexin A2 positively contributes to the malignant phenotype and secretion of IL-6 in DU145 prostate cancer cells. Int J Cancer 2009, 124:68-74.

38. Lokman NA, Ween MP, Oehler MK, Ricciardelli C: The role of annexin A2 in tumorigenesis and cancer progression. Cancer Microenviron, 4:199-208.

39. Zhai H, Acharya S, Gravanis I, Mehmood S, Seidman RJ, Shroyer KR, Hajjar KA, Tsirka SE: Annexin A2 promotes glioma cell invasion and tumor progression. J Neurosci, 31:14346-14360.

40. Wang CY, Chen CL, Tseng YL, Fang YT, Lin YS, Su WC, Chen CC, Chang KC, Wang YC, Lin CF: Annexin A2 silencing induces $G 2$ arrest of non-small cell lung cancer cells through p53-dependent and -independent mechanisms. J Biol Chem 2012, 287:32512-32524.

41. Leevers SJ, Marshall CJ: Activation of extracellular signal-regulated kinase, ERK2, by p21 ras oncoprotein. EMBO J 1992, 11:569-574.

42. Medina A, Ghahary A: Transdifferentiated circulating monocytes release exosomes containing 14-3-3 proteins with matrix metalloproteinase-1 stimulating effect for dermal fibroblasts. Wound Repair Regen 2010 18:245-253.

43. Deng M, Tang H, Zhou Y, Zhou M, Xiong W, Zheng Y, Ye Q, Zeng X, Liao Q, Guo X, Li X, Ma J, Li G: miR-216b suppresses tumor growth and invasion by targeting KRAS in nasopharyngeal carcinoma. J Cell Sci 2011, 124:2997-3005.

44. Ali S, Banerjee S, Logna F, Bao B, Philip PA, Korc M, Sarkar FH: Inactivation of Ink4a/Arf leads to deregulated expression of miRNAs in K-Ras transgenic mouse model of pancreatic cancer. J Cell Physio/ 2012, 227:3373-3380

45. Scapoli L, Palmieri A, Lo Muzio L, Pezzetti F, Rubini C, Girardi A, Farinella F, Mazzotta M, Carinci F: MicroRNA expression profiling of oral carcinoma identifies new markers of tumor progression. Int J Immunopathol Pharmacol 2010, 23:1229-1234.

46. Zhang P, Ma Y, Wang F, Yang J, Liu Z, Peng J, Qin H: Comprehensive gene and microRNA expression profiling reveals the crucial role of hsa-let-7i and its target genes in colorectal cancer metastasis. Mol Biol Rep 2012, 39:1471-1478.

47. Iorio MV, Ferracin M, Liu CG, Veronese A, Spizzo R, Sabbioni S, Magri E, Pedriali M, Fabbri M, Campiglio M, Menard S, Palazzo JP, Rosenberg A, Musiani P, Volinia S, Nenci I, Calin GA, Querzoli P, Negrini M, Croce CM: MicroRNA gene expression deregulation in human breast cancer. Cancer Res 2005, 65:7065-7070.

48. Takahashi H, Kanno T, Nakayamada S, Hirahara K, Sciume G, Muljo SA, Kuchen S, Casellas R, Wei L, Kanno Y, O'Shea JJ: TGF-beta and retinoic acid induce the microRNA miR-10a, which targets $\mathrm{Bcl}-6$ and constrains the plasticity of helper T cells. Nat Immunol 2012, 13:587-595.

49. Yan Y, Luo YC, Wan HY, Wang J, Zhang PP, Liu M, Li X, Li S, Tang H: miR$10 \mathrm{a}$ is involved in metastatic process by regulating EphA4-mediated epithelial-mesenchymal transition and adhesion in hepatoma cells. Hepatology 2013, 57(2):667-670.

50. Tauro BJ, Greening DW, Mathias RA, Mathivanan S, Ji H, Simpson RJ: Two Distinct Populations of Exosomes Are Released from LIM1863 Colon Carcinoma Cell-derived Organoids. Mol Cell Proteomics, 12:587-598.

51. de Gassart A, Geminard C, Fevrier B, Raposo G, Vidal M: Lipid raftassociated protein sorting in exosomes. Blood 2003, 102:4336-4344.

52. Pant $\mathrm{S}$, Hilton $\mathrm{H}$, Burczynski ME: The multifaceted exosome: biogenesis, role in normal and aberrant cellular function, and frontiers for pharmacological and biomarker opportunities. Biochem Pharmacol 2012, 83:1484-1494

53. Stenmark H: Rab GTPases as coordinators of vesicle traffic. Nat Rev Mol Cell Biol 2009, 10:513-525.

54. Stenmark H, Olkkonen VM: The Rab GTPase family. Genome Biol 2001, 2. REVIEWS3007.

55. Chen EH, Olson EN: Unveiling the mechanisms of cell-cell fusion. Science 2005, 308:369-373.

56. Tachibana I, Hemler ME: Role of transmembrane 4 superfamily (TM4SF) proteins CD9 and CD81 in muscle cell fusion and myotube maintenance. J Cell Biol 1999, 146:893-904

57. Parthasarathy V, Martin F, Higginbottom A, Murray H, Moseley GW, Read RC, Mal G, Hulme R, Monk PN, Partridge LJ: Distinct roles for tetraspanins CD9,
CD63 and CD81 in the formation of multinucleated giant cells. Immunology 2009, 127:237-248.

58. Wolfsberg TG, Primakoff $P$, Myles DG, White JM: ADAM, a novel family of membrane proteins containing A Disintegrin And Metalloprotease domain: multipotential functions in cell-cell and cell-matrix interactions. J Cell Biol 1995, 131:275-278.

59. Carloni V, Mazzocca A, Mello T, Galli A, Capaccioli S: Cell fusion promotes chemoresistance in metastatic colon carcinoma. Oncogene 2013, 32(21):2649-2660.

60. Baietti MF, Zhang Z, Mortier E, Melchior A, Degeest G, Geeraerts A, Ivarsson Y, Depoortere F, Coomans C, Vermeiren E, Zimmermann P, David G: Syndecan-syntenin-ALIX regulates the biogenesis of exosomes. Nat Cell Biol 2012, 14:677-685.

61. Terada K, Mori M: Human DnaJ homologs dj2 and dj3, and bag-1 are positive cochaperones of hsc70. J Biol Chem 2000, 275:24728-24734.

62. Kim HP, Morse D, Choi AM: Heat-shock proteins: new keys to the development of cytoprotective therapies. Expert Opin Ther Targets 2006, 10:759-769

63. Clark KL, Zeng Z, Langford AL, Bowen SM, Todd SC: PGRL is a major CD81-associated protein on lymphocytes and distinguishes a new family of cell surface proteins. J Immunol 2001, 167:5115-5121.

64. Zoller M: Tetraspanins: push and pull in suppressing and promoting metastasis. Nat Rev Cancer 2009, 9:40-55.

65. Claas C, Stipp CS, Hemler ME: Evaluation of prototype transmembrane 4 superfamily protein complexes and their relation to lipid rafts. J Biol Chem 2001, 276:7974-7984

66. Rubinstein E: The complexity of tetraspanins. Biochem Soc Trans 2011, 39:501-505

67. Subra C, Laulagnier K, Perret B, Record M: Exosome lipidomics unravels lipid sorting at the level of multivesicular bodies. Biochimie 2007, 89:205-212.

68. Trajkovic K, Hsu C, Chiantia S, Rajendran L, Wenzel D, Wieland F, Schwille P, Brugger B, Simons M: Ceramide triggers budding of exosome vesicles into multivesicular endosomes. Science 2008, 319:1244-1247.

69. Wubbolts R, Leckie RS, Veenhuizen PT, Schwarzmann G, Mobius W, Hoernschemeyer J, Slot JW, Geuze HJ, Stoorvogel W: Proteomic and biochemical analyses of human B cell-derived exosomes. Potential implications for their function and multivesicular body formation. J Biol Chem 2003, 278:10963-10972.

70. Gould GW, Lippincott-Schwartz J: New roles for endosomes: from vesicular carriers to multi-purpose platforms. Nat Rev Mol Cell Biol 2009, 10:287-292.

71. Marzesco AM, Janich P, Wilsch-Brauninger M, Dubreuil V, Langenfeld K, Corbeil D, Huttner WB: Release of extracellular membrane particles carrying the stem cell marker prominin-1 (CD133) from neural progenitors and other epithelial cells. J Cell Sci 2005, 118:2849-2858

72. Bauer N, Wilsch-Brauninger M, Karbanova J, Fonseca AV, Strauss D, Freund D, Thiele C, Huttner WB, Bornhauser M, Corbeil D: Haematopoietic stem cell differentiation promotes the release of prominin-1/CD133containing membrane vesicles-a role of the endocytic-exocytic pathway. EMBO Mol Med 2011, 3:398-409.

73. Teissier $\mathrm{E}$, Pecheur El: Lipids as modulators of membrane fusion mediated by viral fusion proteins. Eur Biophys $J$ 2007, 36:887-899.

74. Rogasevskaia T, Coorssen JR: Sphingomyelin-enriched microdomains define the efficiency of native $\mathrm{Ca}(2+)$-triggered membrane fusion. J Cell Sci 2006, 119:2688-2694.

75. Yuyama K, Sun H, Mitsutake S, Igarashi Y: Sphingolipid-modulated exosome secretion promotes clearance of amyloid-beta by microglia. J Biol Chem 2012, 287:10977-10989.

76. Park KS, Lee HY, Lee SY, Kim MK, Kim SD, Kim JM, Yun J, Im DS, Bae YS: Lysophosphatidylethanolamine stimulates chemotactic migration and cellular invasion in SK-OV3 human ovarian cancer cells: involvement of pertussis toxin-sensitive G-protein coupled receptor. FEBS Lett 2007, 581:4411-4416.

77. Mittelbrunn M, Gutierrez-Vazquez C, Villarroya-Beltri C, Gonzalez S, SanchezCabo F, Gonzalez MA, Bernad A, Sanchez-Madrid F: Unidirectional transfer of microRNA-loaded exosomes from T cells to antigen-presenting cells. Nat Commun 2011, 2:282.

78. Skog J, Wurdinger T, van Rijn S, Meijer DH, Gainche L, Sena-Esteves M, Curry WT Jr, Carter BS, Krichevsky AM, Breakefield XO: Glioblastoma microvesicles transport RNA and proteins that promote tumour growth and provide diagnostic biomarkers. Nat Cell Biol 2008, 10:1470-1476. 
79. Zomer A, Vendrig T, Hopmans ES, van Eijndhoven M, Middeldorp JM, Pegtel DM: Exosomes: Fit to deliver small RNA. Commun Integr Biol 2010, 3(5):447-450.

80. Rabinowits G, Gercel-Taylor C, Day JM, Taylor DD, Kloecker GH: Exosomal microRNA: a diagnostic marker for lung cancer. Clin Lung Cancer 2009, 10:42-46.

81. Taylor DD, Gercel-Taylor C: MicroRNA signatures of tumor-derived exosomes as diagnostic biomarkers of ovarian cancer. Gynecol Oncol 2008, 110:13-21.

doi:10.1186/1476-4598-12-62

Cite this article as: Rappa et al:: Biochemical and biological

characterization of exosomes containing prominin-1/CD133. Molecular Cancer 2013 12:62.

\section{Submit your next manuscript to BioMed Central and take full advantage of:}

- Convenient online submission

- Thorough peer review

- No space constraints or color figure charges

- Immediate publication on acceptance

- Inclusion in PubMed, CAS, Scopus and Google Scholar

- Research which is freely available for redistribution 